\title{
¿Vistiendo España? \\ Trajes e identidad nacional en el reinado de Carlos III ${ }^{1}$
}

\author{
Manuel Amador GonZÁLez FuERTES \\ Universidad Complutense de Madrid \\ manuelamadorgf@gmail.com
}

Fecha de recepción: 30/03/2011

Fecha de aceptación: 07/09/2012

\section{RESUMEN}

Se pretende analizar el discurso identitario subyacente en dos obras impresas durante el reinado de Carlos III: el libro Discurso sobre el luxô de las señoras (1788) y el repertorio de grabados Colección de trages de España (1777-1790) de Juan de la Cruz Cano.

Palabras clave: Traje nacional, Discurso sobre el luxô de las señoras, Colección de trages de España, Juan de la Cruz Cano, Identidad nacional, Grabado.

\section{Dressing Spain? Costume and National Identity in the Reign of Charles III}

\begin{abstract}
This article aims to examine the identity discourse which underlies in two printed works published during the reign of Charles III: the book Discurso sobre el luxô de las señoras (1788) and the collection of engravings Colección de trages de España (1777-1790) by Juan de la Cruz Cano.
\end{abstract}

Key words: National costume, Discurso sobre el luxô de las señoras, Colección de trages de España, Juan de la Cruz Cano, National identity, Engraving.

1 Desearía, en primer lugar, agradecer la invitación cursada por los profesores José Cepeda Gómez y Antonio Calvo Maturana para participar en este monográfico. Además, sin las críticas, los comentarios, las sugerencias y las conversaciones con Maricruz de Carlos, Fernando Remacha, Julián Díaz y José Antonio Guillén el resultado final de estas páginas hubiera sido mucho peor. Por último y aunque ellos no lo sepan, también merecen reconocimiento público Jesusa Vega y Álvaro Molina verdaderos artífices de la idea original de este artículo después de la lectura de su magnífico trabajo. 
La historia que voy a relatarles podría empezar en unos despachos oficiales o paraoficiales similares a donde desempeñan su labor los dibujantes y grabadores de los que trataremos posteriormente. Durante el último tercio del siglo XVIII se pondrá de manifiesto una novedad más importante de lo que generalmente se dice: por primera vez el aparato burocrático de la Monarquía Hispánica puede conseguir información, más o menos fidedigna, de diferentes aspectos de sus territorios peninsulares ${ }^{2}$. El conocimiento de la realidad social resulta fundamental para una coherente política desde el poder en un momento tan cacareadamente reformista en el que, sin duda, a pesar de que algunos consideren que no se puede hablar de Estado, el control de la administración real sobre los gobernados se incrementó considerablemente. Desde el conocimiento pormenorizado de la población del reino ${ }^{3}$, hasta los intentos de la reconstrucción cartográfica del $\mathrm{mismo}^{4}$, pasando por el conocimiento de sus tesoros artísticos $^{5}$, los intentos enciclopédicos sobre su realidad geográfica-institucional ${ }^{6} \mathrm{o}$ económica ${ }^{7}$, o medidas unificadoras desde un punto de vista de la administración

2 Claro que con anterioridad la Monarquía intentó, y en ocasiones consiguió, recapitular información sobre las diferentes localidades que la componían -las Relaciones topográficas de Felipe II o el Catastro de la Ensenada pueden resultar ejemplos suficientemente conocidos- pero se constata cómo será a partir de los años setenta y ochenta del siglo XVIII cuando se incrementan de manera significativa este tipo de iniciativas. Un estudio pionero al respecto, centrándose en el contexto de Extremadura: RodRíGUEZ CANCHO, M.: La Información y el Estado. La necesidad de interrogar a los gobernados a finales del Antiguo Régimen, Cáceres, Universidad de Extremadura, 1992.

3 Sin duda la realización, con fines fiscales, del Catastro de Ensenada supuso un gran paso adelante para el conocimiento de la población en la Corona de Castilla (Censo de población de la Corona de Castilla "Marqués de la Ensenada", 1752 mandado formar por el conde de Valparaiso mediante las reales órdenes de 31.7.1756 y 9.7.1759, basándose en los datos recopilados entre 1750 y 1754 para el catastro del marqués de la Ensenada, Madrid, INE, 1991-1995). Esta labor se sistematizó, dentro de lo posible, y se hizo periódica con los posteriores censos del conde de Aranda (Censo de Aranda, Madrid, INE, 1999-2005), el de Floridablanca (Censo español executado de órden del rey comunicada por el Excelentísimo Señor Conde de Floridablanca, Primer Secretario de Estado y del Despacho, en el año de 1787, Madrid, 1787 -con facsímil en Madrid, INE, 1987-) y el de Godoy (Censo de la población de España de el año de 1797 executado por orden del rey en el de 1801, Madrid, Vega y Compañía, 1801 -con facsímil en Madrid, INE, 1994-).

4 En esta labor destacará la figura de Tomás López de quien, de manera póstuma, se publicará una colección de mapas de España (LóPEz, Tomás: Atlas Geográfico de España, que comprehende el Mapa General del Reyno, y los Particulares de sus Provincias, Madrid, s.n., 1804) tras una ingente labor que se iniciará a su regreso de París a la altura de 1760 y concluirá con su muerte en 1802. Sobre su figura y los mapas conservados en la Biblioteca Nacional y en la Real Academia de la Historia: Líter MAYAYo, Carmen: La obra de Tomás López. Imagen cartográfica del siglo XVIII, Madrid, Biblioteca Nacional, 2002; y LóPEz Gómez, Antonio y Manso Porto, Carmen: Cartografia del siglo XVIII. Tomás López en la Real Academia de la Historia, Madrid, Real Academia de la Historia, 2006.

5 Sin duda en esta labor la tarea fundamental fue desarrollada por Antonio Ponz en su Viage de España (A. Ponz, Antonio: Viage de España en que se dá noticia de las cosas mas apreciables y dignas de saberse que hay en ella, Madrid, Viuda de Ibarra, 1776-1794, 18 vols. -con facsímil en Madrid, s.n., 1972-).

6 Cuyo proyecto más ambicioso, aunque a la postre fracasado, sería el Diccionario geográfico-histórico de la Real Academia de la Historia del que, finalmente, sólo se imprimió el tomo correspondiente a las provincias vascas y al reino de Navarra (Diccionario geográfico-histórico de España por la Real Academia de la Historia. Sección I. Comprehende el Reyno de Navarra, Señorío de Vizcaya, y provincias de Álava y Guipúzcoa, Madrid, Viuda de Ibarra, 1802 -con facsímil en La Coruña, 2010-).

7 En este apartado la labor más importante se debe a Eugenio Larruga (LARRUga, Eugenio: Memorias políticas y económicas sobre los frutos, comercio, fábricas y minas de España, Madrid, 1787-1800, 45 vols. -con facsímil en Zaragoza, Institución "Fernando el Católico", 1995-1996-). 
judicial $^{8}$... durante los reinados de Carlos III y Carlos IV el poder central intentó conocer mejor la realidad social, económica y cultural de sus dominios, presentando como coherente coartada la necesidad de este conocimiento para un mejor gobierno, sin olvidar que tal información permitía, también, una mayor facilidad en el control de los súbditos y un proceso de homogeneización imprescindible desde cualquier tipo de instancia de poder. Pero este incremento del conocimiento también trajo consigo una ligera, por lo menos al principio, modificación de los planteamientos mentales de los gobernantes. Por primera vez se podía pensar de manera relativamente efectiva en los territorios peninsulares como lugares manejables y humanamente cuantificables. Se podía gobernar sobre "un todo" del que se recibía una información coherente -no parece que fueran muy conscientes del proceso de homogeneización desvirtuador de la realidad que tal información conllevaba- y al que se podía tratar de manera conjunta. Así, el ideal absolutista de los primeros Borbones se podría realizar a través de una maquinaria administrativa oficial o que permitiese incrustar en las entidades locales el poder monárquico. Pero lo que ahora interesa no es tanto el camino hacia la absolutización de la política regia, el elemento sin duda más importante de esta evolución, como la posibilidad de interpretar todo el territorio peninsular como una entidad coherente a la que no les parecía descabellado denominar España.

Dilucidar, a través del ejemplo concreto de un elemento cultural tan identificativo como es el de la vestimenta, las interpretaciones que durante el reinado de Carlos III pudieron propiciar desde un punto de vista de la identidad colectiva la polémica sobre una posible creación de un traje nacional femenino y la aparición de la primera colección de grabados de trajes editados en el reino será el objetivo básico de las hojas que siguen.

Pero antes de seguir adelante resultaría conveniente fijar determinados puntos de partida. En primer lugar, convendría señalar la actualidad que desde un punto de vista historiográfico tiene el tema del desarrollo histórico del nacionalismo y, en este caso, de sus orígenes. Tres elementos se reúnen, desde nuestro punto de vista, para el desarrollo de este tipo de análisis. En primer lugar, la construcción de nuevas realidades nacionales tras la caída del muro de Berlín ha fomentado un regreso al tema del nacionalismo que, en un segundo punto, se ha visto favorecido por unas novedosas interpretaciones teóricas que, tras superar el esencialismo burgués de la configuración nacional del siglo XIX, han puesto en duda las interpretaciones «contemporaneístas» de los politólogos contrarios a la existencia de realidades nacionales antes de la Revolución Francesa. Nos encontramos así en un momento en el que la multiplicidad de enfoques -y este es el tercer elemento a destacar- es la característica fundamental de los estudios sobre las identidades nacionales. La severa crítica actual a las teorías politológicas en boga hace un par de décadas, y todavía con productivos defensores,

8 Nos referimos, en este caso, a las modificaciones en los corregimientos que con carácter general para todos los territorios peninsulares se incluyen en la Real Cédula sobre corregimientos de abril de 1783 que, acompañada con su respectiva Instrucción en 1788, permitió la reorganización de la administración judicial de la Monarquía en los territorios peninsulares, creándose la carrera de varas y tratando a todo el territorio peninsular (junto a las islas) como una entidad común (GAY I EsCODA, Josep María: «La culminación de las reformas de la administración municipal durante la Ilustración: el establecimiento de la carrera de corregimientos y varas y la instrucción de Corregidores», Documentación Jurídica, 60 (1988), pp. 1.639-1.759). 
que hacían de la nación una entidad contemporánea constituida por elites dirigentes en función de unas variables de mayor o menor consideración -idioma, procesos de escolarización, influencias de la evolución del capitalismo, difusión de la imprenta, diferenciaciones étnicas, etc. - han derivado en una enorme variedad de enfoques que se relacionan con la "explosión" de interpretaciones historiográficas características de la actualidad: desde las muy influyentes teorías entre los historiadores españoles de la "imaginación" de la "comunidad" de Benedict Anderson o de la "invención" de la "tradición" de Eric Hobsbawm, hasta la revalorización de los aspectos culturales, simbólicos, psicológicos o de género y, dentro de ellos, un replanteamiento de sus orígenes históricos. El proceso de síntesis de las nuevas aportaciones, por lo menos de momento, resulta imposible y los acercamientos a la nueva realidad interpretativa se presentan ante el investigador más como novedosas e interesantes hipótesis y puntos de partida que como escuelas definidas y sólidas en sus propuestas. La necesaria labor crítica ha sido exitosa pero, como en otros muchos aspectos de la historiografía actual, la construcción de nuevas teorías de carácter general ha sido muy endeble?

La actitud crítica de los llamados "contemporaneístas" - defensores del surgimiento nacional tras la Revolución Francesa- hacia la teoría general "esencialista" -partidaria de la existencia per se de un carácter nacional a lo largo de la historia- se ha transformado en una actitud defensiva frente a las diferentes preguntas que no pueden responder de otros especialistas y, en lo que ahora nos ocupa, los que se han dado en llamar "perennialistas" quienes constatan la existencia de un variable concepto histórico de nación y de identificación grupal antes de la Revolución Francesa y se preguntan cómo pudo influir dicho concepto en el desarrollo del concepto de "nación" defendido por la revolución liberal burguesa y aceptado como canónico en los estudios posteriores ${ }^{10}$.

9 La labor de síntesis Anthony D. Smith a lo largo de su trayectoria investigadora puede servir de introducción para una primera aproximación sobre estos temas. Tres de sus libros reflexionan sobre las principales teorías sobre el concepto de nación y el nacionalismo: Sмітн, Anthony D.: Las teorías del nacionalismo, Barcelona, Península, 1976 (1ª edición, Londres, 1971); Sмiтн, Anthony D.: Nacionalismo y Modernidad. Un estudio crítico de las teorías recientes sobre naciones y nacionalismo, Madrid, Istmo, 2000 ( $1^{\text {a }}$ edición, Londres y Nueva York, 1998); y SмIтн, Anthony D.: Nacionalismo: teoría, ideología, historia, Madrid, Alianza, 2004 ( $1^{\text {a }}$ edición, Cambridge, 2001).

10 Es difícil sintetizar la evolución de las posturas críticas sobre el concepto de nación al margen de los textos clásicos de la teoría "contemporaneísta" cuyos máximos representantes pudieran ser Ernest Gellner o Elie Kedourie. Como suele ocurrir en muchas ocasiones, las posiciones hegemónicas que parecía poseer esta visión no eran tan generales como se creían. En diferentes países y al margen de los estudios de estos politólogos, la noción de nación pervivía con mayor o menor peso de "esencialismo" decimonónico provocando como consecuencia una serie de estudios que superaban tal "esencialismo" pero que se situaban al margen de las posiciones vigentes en el ámbito de la ciencia política. En el caso español, figuras insignes como Julio Caro Baroja o José Antonio Maravall pueden simbolizar bien a este tipo de investigadores. Coyunturas históricas determinadas y nuevos planteamientos metodológicos pondrán en duda la validez de la tesis "contemporaneísta" desde diferentes disciplinas científicas ampliando el marco de visión. En este punto los trabajos del propio Smith, de los ya citados Hobsbawm y Anderson y de otros como Adrian Hastings, John A. Armstrong o Liah Greenfeld ayudaron a poner en cuestión la teoría "contemporaneísta" y a reforzar la llamada teoría "perennialista". En el enfoque de los planteamientos "perennialistas" cabría destacar, sólo como referentes bibliográficos básicos, los siguiente trabajos: Seton Watson, Hugh: Nations and States. An Enquiry into the Origins of Nations and the Politics of Nationalism, Boulder, Westview Press, 1977; Armstrong, John A.: Nations before Nationalism, Chapell Hill, University of North Carolina Press, 1982; Hastings, Adrian: La construcción de las nacionalidades, Madrid, Cambridge University Press, 2000 ( $1^{\text {a }}$ edición, Cambridge y 
$\mathrm{Y}$, en el fondo, aquí es donde empieza el problema de la incomunicación. Al destruir el concepto de "nación" se torna, en muchos casos, imposible establecer un diálogo entre los especialistas. Finalmente la noción de nación que pueda defender un "perennialista" no es aceptada por un "contemporaneísta" que la considera poco concreta, mientras que la definición del segundo es demasiado estricta y limitada para el primero. Apuntado el que consideramos fondo del problema, la resolución del mismo, sinceramente, no está en nuestras manos aunque quizá podamos apuntar, para poder continuar con el texto, que la definición es uno de los puntos sobre el que los especialistas tienen que hacer más hincapié. La variabilidad histórica del concepto nos parece evidente y negarla ayuda poco a la comprensión del mismo. Quizá sea precisamente en esta historicidad (que en el fondo no es más que fomentar lo particular para una mejor explicación de la realidad) donde los historiadores tengamos más que aportar en el debate. Conseguir contextualizar temporalmente el concepto de nación y sus posibles representaciones factuales debe ser objetivo insoslayable en nuestros estudios. Y, en la medida de nuestras posibilidades, es lo que intentaremos llevar a cabo a lo largo del artículo.

Para el análisis del caso que proponemos -un folleto, el Discurso sobre el luxô de las señoras, y proyecto de un trage nacional, y un repertorio de grabados, la Colección de trajes de España de Juan de la Cruz Cano y Olmedilla- intentaremos contextualizar la emisión de dos discursos coetáneos que pudieran interpretarse como posibles antecedentes de una visión "nacional" -entre comillas- del proceso identitario de una comunidad. Las escasas huellas dejadas por la recepción de dichos discursos, aunque se tendrán en cuenta en el análisis, impiden, por lo menos por ahora, profundizar en su variación histórica.

A la altura de 1788 la Imprenta Real de Madrid -institución oficial de la Monarquía- dará a la luz un folleto con un título, a primera vista, asombroso: Discurso sobre el luxô de las señoras, y proyecto de un trage nacional ${ }^{11}$. A pesar de este título, que resulta sorprendente por lo que pudiese denotar de consolidación de la identidad nacional en una época muy temprana, la lectura del folleto no cubre, en un primer momento, las expectativas "nacionales" creadas pero, como se verá más adelante, contendrá una serie de reflexiones "patrióticas" que, a la postre, lo situarán en el discurso habitual de la Ilustración sobre la nación en el momento de su publicación ${ }^{12}$.

Nueva York, 1997) y Greenfeld, Liah: Nacionalismo. Cinco vías hacia la modernidad, Madrid, CEPyC, 2005 ( $1^{\mathrm{a}}$ edición, Cambridge, 1992).

11 Discurso sobre el luxô de las señoras, y proyecto de un trage nacional, Madrid, Imprenta Real, 1788. Parece que de este folleto la Imprenta Real tiró dos ediciones distintas el mismo año, incorporándose en ambas tres grabados con los tipos de trajes principales que describe la autora. El Discurso ha tenido fortuna posterior contando con tres ediciones facsímiles contemporáneos, dos en Madrid (1985 y 1987) y otra en Valladolid (2005). Reproducido en: http://books.google.es/books?id=F5vfD_r69GMC\&pg=PP2\&dq=discurso+sobre+el +luxo\&hl\#v

12 Desde distintas perspectivas han tratado sobre esta propuesta y sus repercusiones: Demerson, P. de: María Francisca de Sales Portocarrero, condesa de Montijo. Una figura de la Ilustración, Madrid, Editora Nacional, 1975, pp. 149-168; FernándeZ Quintanilla, Paloma: La mujer ilustrada en la España del siglo XIII, Madrid, Ministerio de Cultura, 1981; Bolufer Peruga, Mónica: Mujeres e Ilustración. La construcción de la feminidad en la España del siglo XVIII, Valencia, Diputación de Valencia, 1998, pp. 169-210; y MolınA, Álvaro y VeGA, Jesusa: Vestir la identidad, construir la apariencia. La cuestión del traje en la España del siglo XVIII, Madrid, Ayuntamiento de Madrid, 2004, pp. 142-159. 
En una apretada síntesis del opúsculo, su presunta autora - escondida bajo las iniciales M. O. ${ }^{13}$ - propondrá al conde de Floridablanca ${ }^{14}$ la instauración de un traje nacional -en realidad tres con hasta nueve variantes ${ }^{15}$ - para la vestimenta de la mujer española. Tal medida evitaría el despilfarro que la coquetería femenina causaba y, además, fomentaría la industria textil autóctona. Como buen texto ilustrado será este elemento reformador de mejora económica el que vertebre el Discurso, aunque la autora del mismo, cercana sin duda a la política reformista de Floridablanca, insistirá a lo largo del texto en su vertiente patriótica. Sin ir más lejos, el texto se inicia con una justificación de este cariz:

Animada de un verdadero patriotismo, dirigido al bien del Estado y de cada individuo en particular, propuse entre los Amigos de mi tertulia, quan útil seria para destruir el pernicioso luxô de las Damas en vestir, señalarlas los ayrosos trages, que al mismo tiempo que evitasen la introducción de las modas extrangeras con que nos arruinamos, caracterizasen la Nacion, distinguiesen la gerarquia de cada una, nos libertasen de las ridiculeces con que casi siempre nos adornamos, solo por ser moda, segun publican quatro Extrangeros que nos llevan muchos millones, y fomentasen nuestras Fábricas y Artesanos. ${ }^{16}$

No debe interpretarse esta declaración como un simple artificio retórico pues tal proclama no deja de ser consecuencia, más o menos consciente, del "amor a la patria" del pensamiento grecolatino que tuvo una evolución azarosa a lo largo de los

13 Resulta un poco extraño el secretismo que envuelve a la autora del opúsculo pues ante una medida que causaría tan grandes mejoras no parece muy lógico que la artífice mantuviera el anonimato. M. O. se presenta como una patriótica mujer preocupada por resolver a un nivel práctico -denosta en el propio texto todo tipo de planteamiento teórico- un problema, el del lujo en la vestimenta femenina, que, según ella, arruina a buen número de familias hispanas. El personaje, real o figurado, no pertenece a los elementos reaccionarios de la sociedad pues, según sus palabras, tiene su propia tertulia pero, sin embargo, considera imprescindible la intervención de un varón para la revisión del texto: "pedí á uno de los de mas confianza que me hiciese el favor de ir formando el proyecto conforme á la idea que me habia propuesto y le iria explicando, y con efecto se verificó su extension en los términos que contiene el adjunto papel» (Discurso, s.f.).

14 A través de una supuesta carta remitida al conde fechada el 15 de febrero de 1788 (Discurso, s. f.).

15 En los primeros artículos de su "Instrucción para el establecimiento de un trage mugeril nacional" (Discurso, pp. 41-57) se describirán los tres trajes propuestos (Española, Carolina y Borbonesa o Madrileña) y sus variantes: «IV. En la Española se deberán emplear los géneros más exquisitos y de mejor gusto de nuestras Fábricas, adornando este trage de tal suerte, que puedan usarle con ciertas restricciones ó amplitudes las Señoras principales en los dias de mayor ostentacion y lucimiento. V. La Carolina ha de ser ménos costosa que la Española, asi por la calidad de la tela que en ella se emplee, como porque su corte ha de tener ménos follage, para que no sea muy gravosa su compra á las que deben usarlo: pero se ha de procurar tambien que sea de mucha gracia, y que admita mas ó ménos adorno para los fines que despues se dirán. VI. La Borbonesa ó Madrileña ha de ser el trage ménos costoso de los tres, y de cierto corte tan sencillo, que sin perjuicio de su buen ayre dexe libertad á las Señoras para manejarse, y pueda admitir algunos otros adornos quando se le deban poner. VII. Cada uno de estos tres trages Española, Carolina, y Borbonesa ó Madrileña ha de dividirse en tres clases diferentes, sin alterarse cosa alguna en su sustancia; pues esta variacion solo consistirá en los accidentes de la calidad ó el color del género y de sus guarniciones» (Discurso, pp. 42-44).

16 Discurso, s. f. Cursiva nuestra. La apelación patriótica vuelve a repetirse en el texto posteriormente: «Si en vez del espiritu patriótico que me anima en el momento que tomo la pluma para escribir este papel, me dexase llevar del deseo ambicioso de adquirir aplausos de erudita, daria principio á mi discurso con una multitud de sucesos memorables, y autoridades célebres de la historia antigua y moderna, que comprobasen el gravámen que se sigue al Estado y á las familias del demasiado luxô en los vestidos» (Discurso, p. 9 -cursiva nuestra-). 
siglos para instalarse en el pensamiento ilustrado español, como ha estudiado Mario Onaindía ${ }^{17}$. Nos encontramos así con un pequeño trazo de uno de los componentes de los que puede surgir un pensamiento de tipo nacional con un pedigree clásico incuestionable y que hay que tomar en cuenta en la historia general del pensamiento de la identidad nacional antes del liberalismo. Pero el patriotismo no es un sentimiento nacional ${ }^{18} \mathrm{y}$ en este texto, como en muchos otros textos ilustrados se utiliza como una apoyatura ideológica más o menos neutra en pos de la implantación de las reforma propuestas.

Otro elemento significativo en lo aquí tratado aparece en el Discurso sobre el luxô que merece un comentario individualizado. $Y$ este no es otro que la percepción que tiene la autora sobre lo que es España o, en otros términos, a qué españolas debe afectar la medida de la creación de un traje nacional. Respecto a este punto nuestra sorpresa también tendría que ser sólo relativa. En el artículo XI de la Instrucción que acompaña al texto se nos dice literalmente que «no parece que convendria por ahora extender la gracia de vestirse con trage nacional á otras Señoras mas que á las Grandes de España, y á las mugeres, madres, hijas ó hermanas de los que tienen tratamiento de Excelencia, Ilustrisima ó Señoría, ó que están empleados en el Real servicio, así Militar como de Rentas» ${ }^{19}$.

No parece que la inmensa mayoría de las españolas -a pesar de la aparición del condicional y de las palabras "por ahora"- tuvieran que preocuparse mucho por un cambio en su indumentaria. Realmente la propuesta se centraba en las mujeres nobles y las relacionadas familiarmente con la administración de la Monarquía. Pero lo más significativo no era el escaso número de las mujeres afectadas por la medida, ni siquiera la sinécdoque de tomar el todo por una parte, sino que tal elección se realizaba por criterios fundamentalmente estamentales. Más allá de la minuciosidad con la que la autora pretende individualizar - a través de la vestimenta a los diferentes grupos sociales- intentando establecer una división social en función del vestido para evitar el confusionismo provocado por la inclusión de elementos burgueses con suficiente capacidad económica para disputar la preeminencia social nobiliaria respecto a la moda, lo que verdaderamente llama la atención en el texto a los efectos que ahora nos interesan es precisamente que la división del elemento nacional no se establezca espacial sino estamentalmente. El elemento geográfico no juega ningún papel para la autora del proyecto en la determinación de un posible traje nacional femenino.

Las repercusiones posteriores del folleto aclaran sin duda el escaso papel que en este proyecto tenía la perspectiva nacional. Según nos informa Paula de Demerson ${ }^{20}$,

17 OnAINDíA, Mario: La construcción de la nación española: republicanismo y nacionalismo en la Ilustración, Barcelona. Ediciones B, 2002.

18 El patriotismo, surgido en el mundo clásico en relación con el amor a la polis, jugará un papel ideológico importante en el desarrollo de la Ilustración hispana a través de la influencia -infravalorada por parte de la historiografía española- del pensamiento inglés. En el caso hispano, como pone de manifiesto el estudio de Onaindía, esta influencia se desarrolló fundamentalmente entre un considerable grupo de ilustrados miembros de la administración de la Monarquía. El amor a la polis se transformaba en ellos en lealtad y sacrificio hacia la Monarquía, tanto hacia el rey como hacia el reino, pero todavía sólo se vislumbraba un acercamiento en términos espaciales hacia el concepto España. Será a partir de 1808, al fijarse geográficamente el concepto de España, cuando la ideología patriótica pueda entrar a formar parte de la corriente nacionalista.

19 Discurso, p. 46.

20 Demerson, op. cit. (nota 11), pp. 155-163. 
el 27 de junio de 1788 el Discurso, tras su publicación, fue enviado a la Junta de Damas con vistas a recabar su opinión sobre el proyecto. La opinión de la Junta no pudo ser más adversa. En un carta de la condesa de Montijo remitida al conde de Floridablanca el 5 de julio de 1788 se rechaza de plano argumentando, entre otras razones, «que la inclinación que hay en nuestro sexo a sobresalir y distinguirse no mira por objeto principal para salir con este fin, ni la preheminencia del nacimiento ni quantas puede haber introducido la Política en el orden social de una Monarquía, sino la que viene por la naturaleza en prendas u dotes de alma y cuerpo, y como en subsidio de ésta la del adorno en los trages, y en último lugar, como subsidiaria también, viene la de diferencia de clases ${ }^{21}$. Sobre la posible identidad del proyecto, por contra, nada se dice. Y en la contrarréplica de la autora, también publicada por la Imprenta Real en $1788^{22}$, acompañada por otro texto de otra supuesta mujer, con siglas M. A. F., que, como hija de militar y habitante de una ciudad de provincia, reafirmaría las opiniones de la autora, tampoco se añaden más matices, en los puntos que nos interesan, al patriotismo ilustrado antes apuntado. Finalmente de la polémica nada quedó, a no ser los tres grabados de trajes propuestos y la recreación de dos de ellos adjuntados por Juan de la Cruz Cano a su colección de trajes de la que se hablará inmediatamente.

De manera paradójica, la figura del grabador Juan de la Cruz Cano y Olmedilla ${ }^{23}$ (6 de mayo de 1734 - 13 de febrero de 1790) ha pasado a la historia más por su Colección de trajes que por su cargo de geógrafo real a pesar de que él recalcase, una y otra vez, tal condición en la publicidad de sus obras ${ }^{24}$. Su gran labor cartográfica, el Mapa de América Meridional ${ }^{25}$, terminada tras diez años de trabajo, fue desechada y criticada por inconveniente en el conflicto político con Portuga ${ }^{26}$. Aunque posteriormente, a la altura de 1802, fue rehabilitado -tras un informe favorable de Tomás López en $1797^{27}$ - con motivo de las nuevas negociaciones diplomáticas con Portugal,

21 Ibidem, p. 371.

22 Respuesta á las objeciones que se han hecho contra el proyecto de un trage nacional para las damas, Madrid, Imprenta Real, 1788.

23 Sobre sus relaciones familiares - era hermano del comediógrafo Ramón de la Cruz- y descendencia: Herrera Vaillant, Antonio A. de: «Don Ramón de la Cruz, hidalgo y poeta de Madrid, y su familia», Hidalguía, 178-179 (1983), pp. 438-453.

24 Resultará significativa esta insistencia. Toda parece indicar que Juan de la Cruz no tuvo nunca un cargo administrativo, simplemente fue pensionado para la realización de un mapa de América del Sur. Cuando por diversas circunstancias que ahora veremos no pudo continuar en la administración y tuvo que enfocar sus actividad profesional al ámbito privado, el cargo de "Geógrafo de S. M." resultaba un buen reclamo comercial aunque no fuera cierto desde un punto de vista institucional.

25 Mapa geográfico de América Meridional Dispuesto y Gravado por D. Juan de la Cruz Cano y Olmedilla, Geogfo. Pensdo. de S. M., individuo de la Rl. Academia de Sn. Fernando, y de la Sociedad Bascongada de los Amigos del Pais, teniendo presentes varios Mapas y noticias originales con arreglo á Observaciones astronómicas; impresa y gravada la letra, por Hipolito Ricarte año 1771, Madrid, s.n., 1775. La catalogación más reciente en: LóPEz y MANso, op. cit. (nota 3), pp. 426-427.

26 A pesar del trabajo realizado, al presentar el mapa a la altura de 1775 Juan de la Cruz fue desacreditado y se mandó retirar el mapa de la circulación al interpretarse que el mismo podía ser una prueba en favor de los argumentos de Portugal en la disputa con esta monarquía en el trazado de fronteras en América del Sur (CuESTA Domingo, Mariano: «Cartografía de América del Sur. Juan de la Cruz», en Milicia y sociedad ilustrada en España y América (1750-1800), Madrid, Deimos, 2003, t. II, pp. 230-231, y LóPEz y MANso, op. cit. (nota 3), pp. 152-153).

27 El informe, fechado el 14 de julio de 1797, llega a las siguientes conclusiones: «Finalmente, concluiré diciendo que, sin embargo de los defectos que tiene este mapa, es un papel de los mejores que tenemos 
quedando para la posteridad como uno de los mejores trabajos cartográficos ilustrados del continente americano ${ }^{28}$, tal redención no pudo disfrutarla al morir en 1790 . El propio Tomás López nos habló de su pobreza y de la gran cantidad de hijos que tenía que mantener. Le conocía bien, habían sido pensionados en París junto a Manuel Salvador Carmona y Alfonso Cruzado a costa de la Real Academia de Bellas Artes de San Fernando desde 1752 hasta $1760^{29}$. La estancia parisina marcará su carrera profesional y será decisiva, como veremos posteriormente, para la realización de su Colección de trajes de España. Además, la frustración profesional, generada por la prohibición de la que sería su mejor obra (a la que había dedicado diez años de su vida), y la necesidad de allegar dinero ${ }^{30}$ serán los puntos de referencia fundamentales desde donde se deberá partir para analizar sus grabados de trajes de España.

Será después de abril de 1776, siguiendo al propio Fernández-Duro, cuando se produzca la defenestración de Juan de la Cruz y cuando se retire de la circulación el mapa de América del $\mathrm{Sur}^{31}$. Aunque no se puede saber cuándo surgió la idea de la Colección de trajes, parece factible considerar que la misma iría tomando cuerpo desde mediados de 1776 cuando Juan de la Cruz dejó de percibir dinero del gobierno y tuvo que enfocar su carrera profesional desde un ámbito estrictamente comercial y particular. Año y medio después, el 2 de septiembre de 1777, la Gaceta de Madrid publicaba el siguiente anuncio:

impresos de esta parte de la tierra, pues se emprenden pocas veces mapas de igual magnitud, porque se necesita mucho tiempo para su composición, muchos documentos, y asciende mucho el gasto, siendo siempre incierto el beneficio; solamente un soberano puede hacer estas obras, ó un cuerpo de letra dos ricos, que los hay en pocas partes; también lo puede ejecutar el brazo eclesiástico, que es poderoso y nunca muere; pero no un particular, en quien faltan las circunstancias expresadas» (FERNÁNDEZ-DURO, Cesáreo: Armada española desde la unión de los reinos de Castilla y de Aragón, Madrid, 1973, t. VII, p. 407).

28 El mapa de Cruz ha devenido en un clásico de la cartografía americana como demuestras los numerosos trabajos específicos que se le han dedicado. Entre ellos destacan: Ristow, Walter W.: «The Juan de la Cruz map of South America, 1775», Studies in geography, 6 (1962), pp. 1-12; Donoso, R.: «El mapa de América Meridional de don Juan de la Cruz Cano y Olmedilla», Revista Chilena de Historia y Geografia, 131 (1963), pp. 121-175; Sмітн, Thomas R.: «Cruz Cano's Map of South America, Madrid 1775; its creation, adversities and rehabilitation», Imago Mundi, XX (1966), pp. 49-78 y VÁzquEZ de AcuÑa, Isidoro: Don Juan de la Cruz su mapa de América meridional (1775) y las fronteras del reino de Chile, Santiago de Chile, Universidad de Santiago, 1984.

29 De regreso a Madrid fue nombrado, no son ciertos reparos, académico supernumerario de la Academia de San Fernando en 1760 y académico de mérito en 1764 (BÉDAT, Claude: La Real Academia de Bellas Artes de San Fernando, Madrid, FUE, 1989, p. 161).

30 Según nos informa el propio Tomás López, Juan de la Cruz sólo recibió 18.000 reales por la realización del mapa, cuando estaba valorado, según estimación de López, en 60.000 reales (FernánDEz-Duro, op. cit. (nota 26), t. VII, p. 402). El propio Fernández-Duro reproduce una carta de Juan de la Cruz al conde de Floridablanca, de 3 de octubre de 1787, en la que, tras describir una posición económica desastrosa, le solicitaba ser agregado al archivo de la Secretaría de Estado como "geógrafo político que sabe por los tratados los intereses de la Monarquía tocante á sus posesiones" o como "geógrafo histórico, imprimiendo una geografía ilustrada que tiene traducida de Abraham du Bois y que se puede aumentar con la nueva del presidente Bousching". La suplica sólo consiguió una gratificación de 750 reales por el famoso conde (FERNÁNDEZ-Duro, op. cit. (nota 26), t. VII, pp. 408-409).

31 Ibidem, t. VII, p. 408. 
“Colección de trages Españoles grabados por D. Juan de la Cruz Pensionista de S. M: primer quaderno que contiene 12 láminas. Las de los siguientes se iran dando de dos en dos. Venderase en la Libreria de Copin carrera de S. Gerónimo". ${ }^{32}$

Esta es la primera información que se ha encontrado de la Colección de trajes de Juan de la Cruz: doce láminas de "trages Españoles" que se vendían en la librería Copin, especializada en grabados, en la Carrera de San Jerónimo. Además de remarcar su vinculación con el rey ("pensionista de S. M.") se informa de que los nuevos grabados se presentarán al público en parejas sin proporcionar información del precio de las láminas ${ }^{33}$.

¿Qué se iba a encontrar un posible comprador entre estas láminas? La relación de la primera docena de grabados presenta una variedad que podía ser atractiva: oficios populares urbanos, por no decir de la Corte, tales como diferentes vendedores (la gacetera, la naranjera, el aguador - por partida doble-), tipos populares como un ciego, una paya, un par de majos y una petimetra, la autoridad representada por un alguacil $\mathrm{y}$ algunos personajes regionales conocidos, como una pasiega y un andaluz bastante cercano a un posible contrabandista con su embozo.

El posible comprador encontrará ya en en este primer cuaderno la principal característica de la Colección: la mezcla, más o menos armónica, de diferentes tipologías de grabados (vendedores, representaciones regionales, estampas costumbristas...) que de manera novedosa en España pretenderán reflejar, según el título de "Colección de trages Españoles", una posible realidad de lo que se pudiera entender, tanto por el autor como por el público, como "español".

La sucesión de anuncios en la Gaceta de nuevos grabados se sucede con buen ritmo y sin mayores novedades desde el 30 de septiembre de 1777, donde se anuncian los grabados decimotercero y decimocuarto hasta el 24 de marzo de 1778, momento en el que se completa el segundo cuaderno llegándose a la estampa número 24 sin ninguna novedad temática destacable. Las parejas suelen tener alguna relación (representaciones de profesiones - choricero $^{34}$ y pescadera o verdulera y naranjero- o de hombres y mujeres de la misma localidad) salvo, quizá, un cierto predominio de representaciones con un carácter más geográfico que social o laboral (artesoneros abulenses, chesos, maragatos y charros) $)^{35}$.

32 Gaceta de Madrid, 2.9.1777.

33 Que, por informaciones posteriores, rondarían los 36 reales o, quizá, algo menos en una posible oferta de lanzamiento.

34 Con respecto a este grabado se puede deslizar un error que dificultaría su explicación y la coherencia de su edición en ese momento en la serie. Aunque represente a un choricero extremeño -como queda reflejado en el dibujo preparatorio conservado en la Biblioteca Nacional (DIB/14/4/20)- no representa a un habitante de Extremadura sino a un vendedor de chorizos extremeños en la Corte presentándose una polisemia en la lámina aunque la supresión en el título definitivo del origen extremeno del vendedor pudiera interpretarse como una elección del elemento profesional sobre el origen geográfico. Algo similar ocurrirá en el caso del Naranjero murciano, aunque en este caso si perviva el origen de la mercancía en el título del grabado.

35 La cadencia en los anuncios en la Gaceta de Madrid es la siguiente: 30.9.1777: 13 (Chorizero) y 14 (Pescadera). 21.10.1777: 15 (Serrano artesonero del partido de Ávila) y 16 (Castellana vieja, del partido de Ávila), anunciados simplemente como "Artesonero y Artesonera". 25.11.1777: 17 (Cheso), 17 (Chesa), 18 (Maragata) y 19 (Maragato). 3.2.1778: 21 (Verdulera) y 22 (Naranjero murciano). 24.3.1778: 23 (Aldeano charro de los caserios de Salamanca) y 24 (Aldeana charra del partido de Salamanca), anunciados solamente como "un Charro y una Charra". 
En apenas seis meses se ha publicado el segundo cuaderno pero habrá que esperar otros seis para el inicio del tercero. En la Gaceta de Madrid del 15 de septiembre de 1778 se anuncia la venta de tres nuevas estampas de la colección entre las que se encontraría la portada de la obra que, según dicho grabado, llevaría como título el siguiente: Colección de trajes de España, tanto antiguos como modernos, Que comprehende todos los de sus Dominios, Dividida en dos Volumenes con ocho quadernos de á doze Estampas cada uno: Dispuesta y Gravada, Por D. Juan de la Cruz Cano y Holmedilla Geografo Pensionado de S. M. é individuo de las Reales Academias de S. Fernando, y Sociedad Bascongada de los Amigos del Pais ${ }^{36}$. Quien hubiese comprado las veinticuatro estampas anteriores conocía ahora que la obra pretendía tener un total de 192 estampas en dos volúmenes ${ }^{37}$. Además del número total de posibles grabados, Juan de la Cruz informaba de que los trajes representados podían ser "tanto antiguos como modernos" aunque hasta ese momento todos los trajes habían sido contemporáneos y, lo que resulta importante para nuestro estudio, se iba a componer tanto de trajes de España como de "todos los de sus dominios" abriendo la posibilidad, en la práctica, de la representación de trajes americanos ${ }^{38}$.

La edición del tercer cuaderno se dilatará en el tiempo durante prácticamente año y medio -desde el 15 de septiembre de 1778 hasta el 31 de marzo de 1780- y se caracterizará por su falta de cohesión interna, aunque cada pareja de grabados que se editaba de manera conjunta sí tuviese una relación directa. Se presentan cuatro trajes locales peninsulares (de Cataluña y Murcia ${ }^{39}$ ) y dos de oficios urbanos (el aceitero y la criada ${ }^{40}$ ) pero se incluyen cuatro de tema americano ${ }^{41} \mathrm{y}$, sobre todo, se introduce la novedad de la representación de dos de los toreros más famosos del momento: Pedro Romero y Joaquín Costillares ${ }^{42}$. Aciertan Jesusa Vega y Álvaro Molina al considerar la inclusión de estos dos grabados como una concesión al público con el objeto de conseguir una venta rápida y abundante ${ }^{43}$ pero aún así, la consecuencia última de tantas novedades, alguna además no anunciada, es la dispersión del concepto de la colección mezclando demasiados elementos que llegan a hacerla incoherente.

36 Reproducido en su totalidad en: http://bibliotecadigitalhispanica.bne.es:80/webclient/DeliveryManag er?pid=174058\&custom_att_2=simple_viewer

37 El comprador también debía ser consciente de que era relativamente habitual en las ventas de grabados que las previsiones iniciales se alterasen aumentando o disminuyendo las colecciones en función de la aceptación del público.

38 Los otros dos grabados anunciados en la Gaceta de dicho día, los números 25 y 26, que representaban a un "catalán" y a una "catalana" no aportaban ninguna novedad respecto a los anteriores (Gaceta de Madrid, 15.9.1778).

39 Son las estampas números 31 y 32 de la Colección que representan a la Arrendadora de la huerta de Murcia y al Arrendador de la huerta de Murcia que se publicitaron en la Gaceta de Madrid del 23 de marzo de 1779 .

40 Corresponden a los números 33 y 34 de la Colección que llevan como título Criada y Azeitero. La información que nos ofrece la Gaceta el 8 de junio de 1779 aclara la relación entre ambos al representar "á un Aceitero y una Criada que baxa por aceite".

41 Son los grabados números 29 (Gíbaro de la isla de Puerto Rico) y 30 (Esclava de Puerto Rico) mencionados en la Gaceta de Madrid del 22 de diciembre de 1778 y los números 35 (India del Perú) y 36 (Española criolla de Lima) anunciados en la Gaceta el 31 de marzo de 1780.

42 Anunciados en la Gaceta como la representación de "dos famosos toreros" (Gaceta de Madrid, 23.10.1778), se trata de los números 27 y 28 de la Colección.

43 Molina y Vega, op. cit. (nota 12), pp. 204-205. 
Mayor coherencia interna tenía el cuarto cuaderno, como se anunciaba en su primer grabado ( $Q$ Quarto quaderno que contiene doce figuras de las Islas Baleares»). Molina y Vega apuntan, otra vez de manera acertada, que esta dedicación exclusiva derivaba de la campaña bélica entablada contra Gran Bretaña para la recuperación de Ibiza que provocó que los temas sobre Baleares pasaran a un primer plano de interés ${ }^{44}$. También en este caso es posible una datación aproximada de las estampas entre el 9 junio de 1780, cuando aparecen anunciadas en la Gazeta las dos primeras, y el 1 de marzo de 1782, cuando se anuncian los dos últimas ${ }^{45}$. La velocidad de producción desciende -tarda un año y nueve meses cuando el anterior cuaderno se estampó en año y medio- y aparecen nuevos colaboradores: Antonio Carnicero y Guillermo Ferrer teniendo además probablemente un motivo de inspiración en una obra anterior de Cristóbal Vilella ${ }^{46}$, los Trajes de los naturales de la Isla de Mallorca ${ }^{47}$. Este oportunismo comercial perjudicó a la larga, de nuevo, la coherente distribución geográfica de los trajes reproducidos en la Colección pues provocaría, como veremos, una sobrerrepresentación de los trajes de las islas Baleares.

Más allá del elevado número de trajes representado, puede resultar interesante relacionar los trajes escogidos por Juan de la Cruz con los diez y ocho dibujos de Cristóbal Vilella ${ }^{48}$. Es bastante probable que tanto Juan de la Cruz como Antonio

44 Ibidem, pp. 200-201.

45 Los anuncios de cada par de grabados y sus motivos son los siguientes: - 9 de junio de 1780: Números 37 (Pagés o payo mallorquín en día de fiesta) y número 38 (Señora mallorquina) (Gaceta de Madrid, 9.6.1780). - 10 de octubre de 1780: Números 39 (Pastor mallorquín) y número 40 (Pastora mallorquina) (Gaceta de Madrid, 10.10.1780), bajo la denominación «un pastor y una pastora de las Islas Baleares». - 24 de noviembre de 1780: Número 41 (Labradora yvizenca) y número 42 (Labrador yvicenco) (Gaceta de Madrid, 24.11.1780 con la siguiente descripción «un Ibicenco y una Ibicenca»). - 7 de agosto de 1781: Número 42 (Menorquina) y número 43 (Mahonés) (Gaceta de Madrid, 7.8.1781), con la descripción «un Mahonés y una Mahonesa de la Isla de Menorca». - 25 de diciembre de 1781: Número 44 (Traginero mallorquín) y número 45 (Marinero mallorquín) (Gaceta de Madrid, 25.12.1781). - 1 de marzo de 1782: Número 46 (Pagés) y número 47 (Menestrala) (Gaceta de Madrid,1.3.1782), especificando su origen geográfico: «un Pajés y una Menestrala de Mallorca».

46 El álbum original no aparece fechado pero según Isabel Azcárate fue entregado por el duque de Béjar al príncipe de Asturias, junto con otras obras, en 1773 (AzCÁRATE LuXÁN, Isabel: «Cristóbal Vilella, pintor y naturalista», en El Arte en las Cortes europeas del siglo XVIII, Madrid, Dirección General de Patrimonio Cultural, 1989, p. 94).

47 Conservados en la Biblioteca de Palacio de Madrid (BP: II/743) con el título: Trajes de los naturales de la Isla de Mallorca sacados del natural y pintados para el Real Gavinete del Principe my señor a quien los dedica por medio del Excelentísimo señor duque de Bejar, Mayordomo Mayor de Su Alteza Real, su author, don Christoual Vilella, Academico de la Real Academia de las tres Nobles Artes de San Fernando. Existe una edición facsímil: Vilella, Cristóbal: Trajes de la Isla de Mallorca, Madrid y Palma de Mallorca, Patrimonio Nacional, 1989.

48 La Colección de Vilella se compone de 18 dibujos con los siguientes títulos y temas según la descripción que acompaña a dichos dibujos: Señore (una señora distinguida) (figura 1), Mozona («medio señora»), Atlota («muchacha»), Riberenca («mugeres de los marineros»), Majorale («mujeres de los mayordomos que los señores tienen en las casas de campo»), Pagese («aldeana»), Espigoladore («lugareña [que va] a recoger las espigas que se quedan en los campos segados»), Entrecavadore («viven de trabajo de escardar los campos sembrados»), Criada, Jaye («mujeres de avansada edad [...]. Suelen hazer su negocio haziendo la vida pordiosera»), Chuyete («dezcendientes de judios»), Manestral («maestros de oficios»), Mariner, Batle («alcalde de villa»), Pagés, Entrecavador («jornaleros que viven de ir a las huertas de verduras del contorno de la ciudad»), Pastor y Traginer de Oly («arriero de azeyte»). 


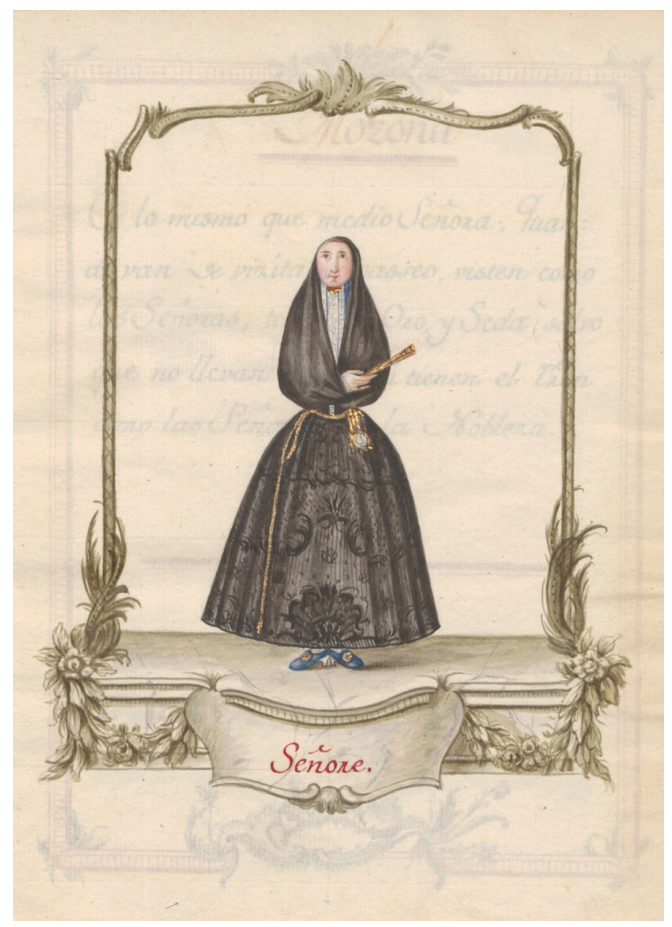

Figura 1. Cristóbal Vilella y Amengual, Señore, s.f. Dibujo. 230 x 175 mms. En Cristóbal Vilella y Amengual, Trajes de los naturales de la Isla de Mallorca, fol. 2. BP: II/743.

Carnicero ${ }^{49}$, el dibujante de cuatro de los ocho dibujos dedicados a la isla de Mallorca y quien trabajaba continuadamente para la Casa Real desde $1775^{50}$, pudiesen conocer los dibujos de Vilella, y aunque no se observa que sirvieran de fuente de inspiración, sí pueden aportar pistas sobre los criterios utilizados por Juan de la Cruz para elegir los temas de sus grabados. No parece que le interese la marginación social de la Jaye o la Chuyete, ni siquiera las capas más deprimidas de la sociedad como los "entrecavadores", la Criada y la Espigoladore. En cambio, se centra en la dignidad de la media nobleza (Señora mallorquina -figura 3-), ve necesario hacerse eco del estamento comercial (Traginero mallorquín) y de la trabajadora urbana (Menestrela), repetir la representación del labriego (Pagés o payo mallorquín en día de fiesta y Pagés), señalar la importancia de la marinería (Marinero mallorquín) y representar el elemento pastoril tanto en su versión masculina (Pastor mallorquín) como femenina (Pastora mallorquina). La elección de esta tipología sí resultaba coherente con el resto de su

49 Antonio Carnicero colaborará solamente en este cuaderno con siete dibujos: Pagés o payo mallorquín en día de fiesta, Señora mallorquina, Pastor mallorquín, Labradora yvizenca, Labrador yvicenco, Mahonés y Marinero mallorquín. En este cuaderno también colaboró con dos dibujos (Pastora mallorquina y Traginero mallorquín) Guillermo Ferrer i Puig, dibujante mallorquín que curiosamente lleva a cabo representaciones que no se encontraban en la Colección de Cristóbal Vilella.

50 Martínez IbÁÑEZ, Ma Antonia: «Biografía y estudio de la obra de Antonio Carnicero Mancio», en $A n$ tonio Carnicero, 1748-1814, Madrid, Ayuntamiento de Madrid, 1997, p. 40. 
Colección aunque con ella empezaba a "naufragar" la división de los dos volúmenes que en la Portada de su obra proponía al incluir la representación de la Señora, en tanto que noble y no plebeya, en el teórico primer volumen dedicado al común ${ }^{51}$.

El quinto cuaderno de la Colección de trajes sí correspondía mejor a las pretensiones manifestadas por Juan de la Cruz en el grabado de la Portada. Siguiendo este primitivo plan se suceden una serie de representaciones de trajes de diferentes localidades peninsulares (el valle del Roncal, Bilbao y Valencia) junto con cuatro prototipos de tipismo cortesano (Modista, Peluquero, Abate y Manteísta) ${ }^{52}$.

Todo parece indicar que la emisión de los grabados 49 y 50 (Roncalés y Roncalesa) -publicitados en la Gaceta el 9 de abril de 1782- supuso un punto de inflexión en la colección pues los siguientes grabados -el 51 y 52-tardaron más de un año en ponerse a la venta, en concreto el 16 de septiembre de 1783, lo que provocaría que el tiempo para concluir el cuaderno se retrasara de nuevo hasta llegar a los dos años (desde el 9 de abril de 1784 al 23 de abril de 1783). La continuidad de la Colección no estaba clara. Un mes después de la puesta a la venta de estos dos primeros grabados de este cuaderno, Juan de la Cruz anunció en la Gaceta lo que dio en llamar un "suplemento á la colección de los [trajes] de España" bajo el título de Quaderno de trages de teatro en donde se retrataban dos de los mejores actores del momento: Miguel Garrido y José Espejo ${ }^{53}$. Más allá de las evidentes relaciones que estas representaciones establecen entre Juan de la Cruz y el ambiente teatral madrileño a través, principal pero no solamente, de su hermano Ramón, estos grabados serán un antecedente de otros que sí aparecerán posteriormente formando parte de la Colección de trajes de España al no tener, probablemente, mucho éxito esta nueva aventura editorial ${ }^{54}$.

Tras el parón de más de un año, sin embargo, los otros diez grabados salieron a la luz en poco más de siete meses con la ayuda de cuatro dibujos realizados por Luis Paret durante su estancia en Bilbao, otros cuatro sobre tipos cortesanos que parece factible que pudieran ya estar realizados por Manuel de la Cruz y Juan de la Cruz,

51 En el grabado de la Portada especificaba que "el primer Volumen de esta Coleccion que se dá al publico de dos en dos estampas, saldrán los Trajes mas usuales de la Pleve del Reyno; y en el Segundo, los mas raros de la Nobleza de toda la Monarquia, estilados de dos Siglos á esta parte".

52 Los anuncios en la Gaceta de Madrid aparecieron en las siguientes fechas: - 9 de abril de 1782: Números 49 (Roncalés) y 50 (Roncalesa) (Gaceta de Madrid, 9.4.1782), bajo la denominación de "un Roncales y un Roncalesa del valle de Roncal en el Reyno de Navarra". - 16.9.1783: Números 51 (Criada de Bilbao) y 52 (Ciudadana de Bilbao) (Gaceta de Madrid, 16.9.1783). - 17.10.1783: Números 53 (Aldeana de las cercanías de Bilbao) y 54 (Jebo o aldeano de las cercanías de Bilbao) (Gaceta de Madrid, 17.10.1783). - 23.12.1783: Números 55 (Modista) y 56 (Peluquero) (Gaceta de Madrid, 23.12.1783). - 27.2.1784: Números 57 (Abate) y 58 (Manteísta) (Gaceta de Madrid, 27.2.1784), bajo la significativo título de "dos estudiantes". - 23.4.1784: Números 59 (Valenciano) y 60 (Valenciana) (Gaceta de Madrid, 23.4.1784).

53 La noticia completa del anuncio es la siguiente: «Dos estampas del quaderno de trages del teatro, que servirá de suplemento á la coleccion de los de España, grabadas por D. Juan de la Cruz, Geógrafo de S. M., las quales representan á Garrido de Gitano, y á Espejo de Ciego. Se hallarán á los precios consabidos, con los Mapas de Inglaterra, Irlanda, Jamayca y demas obras del autor, en casa de D. Miguel Copin, Carrera de S. Gerónimo» (Gaceta de Madrid, 7.5.1782).

54 El Quaderno de trages de teatro se completará con un tercer grabado titulado Traje de theatro a la antigua española del que sólo sabemos que se editará antes del 16 de marzo de 1787 pues en esa fecha la Gaceta informa de su existencia: "Con ellas se completan 6 quadernos de á 12 trages cada uno, hará el número 72 [se refiere a los grabados que está anunciando en ese número]; $\sin$ las 3 que contiene del teatro y el frontispicio.» (Gaceta de Madrid, 16.3.1787). 
y un par de grabados de tema valenciano en donde se puso de manifiesto, en el caso de la Valenciana, la colaboración local auspiciada por el propio Juan de la Cruz en el grabado de la Portada de su obra en donde "los curiosos de fuera ó dentro de la Corte que gustasen comunicar algun dibujo de vestuario poco conocido y existente en algun Pueblo, Valle, ó Serrania de la Peninsula, seran recompesados con otros tantos quadernos, como figuras remitan en Carta, ó sin ella, a dicho autor".

Inmediatamente, en solo dos meses, nuestro grabador se lanzó a editar las dos primeras estampas del sexto cuaderno de su Colección de trajes. El anuncio de la Gaceta presenta el suficiente interés como para reproducirlo en su integridad:

Dos estampas nuevas números 61 y 62 de la coleccion de trages de España y sus dominios, grabada por D. Juan de la Cruz Geógrafo de S. M. Con ellas empieza el $6^{\circ}$ quaderno que contendrá 16 laminas con 3 figuras cada una de vestuarios Americanos, representándose en ellas igualmente todas las castas que hay en las posesiones Españolas en el nuevo mundo, haciéndose ver en las actuales el Español y la India que producen á el mestizo; y este con otra India del Collote. Se hallarán á los precios consabidos de 2 y 4 rs. sin iluminar é iluminadas con todas las precedentes en Madrid casa de Copin carrera de S. Gerónimo. ${ }^{55}$

Se iniciaba, según palabras del propio autor, un nuevo cuaderno, con dieciséis láminas en lugar de doce, en donde se representarían las diferentes castas americanas con sus respectivas vestimentas. Con esta decisión, el concepto de la Colección se transformaba profundamente como queda constatado en la publicidad de las seis láminas que finalmente se imprimieron. Así, en los tres anuncios se expresa claramente que la Colección es de "trages de España y sus dominios" 56 . Los posibles compradores no tendrían porque sentirse engañados pues ya habían sido advertidos en el grabado de la Portada que se había distribuido anteriormente y, además, no era la primera vez que aparecían grabados de los territorios americanos. Aún así, esta decisión y el hecho de que, por lo menos en teoría, se formase un cuaderno más voluminoso le daría una singularidad que no tendría ninguna repercusión porque, finalmente, sólo se imprimieron seis grabados de este tipo ya que, a partir del número 67, los otros seis de este cuaderno se dedicarán a cinco trajes de las Islas Canarias $^{57}$ y otro a un cochero de línea ${ }^{58}$.

Explicar estos cambios, en un cuaderno que se extendía ya a lo largo de dos años y nueve meses, se hace difícil, pero convendría llamar la atención sobre las autorías de los dibujos preparatorios: los primeros tres dedicados a las castas americanas y el del Cochero Simon (figura 2) aparecen firmados por Manuel de la Cruz, lo que puede indicar que se hubieran realizado anteriormente o para otros fines, mientras que todos los canarios no tienen firma en cuanto al dibujante. Parece bastante probable, aunque no deja de ser una teoría indemostrable con los datos que hasta ahora se poseen, que estos últimos dibujos le llegaran a Juan de la Cruz de un dibujante

55 Gaceta de Madrid, 22.6.1784.

56 Gaceta de Madrid, 19.11.1784 y Gaceta de Madrid, 17.6.1785.

57 Con los siguientes títulos: Canario de la Gran Canaria, Labradora de la Isla de Tenerife, Viuda noble de las islas Canarias, Isleño de las Canarias y Serrano de la Gran Canaria.

58 Titulado Cochero Simon. Se publicitó en la Gaceta el 15 de noviembre de 1785. 


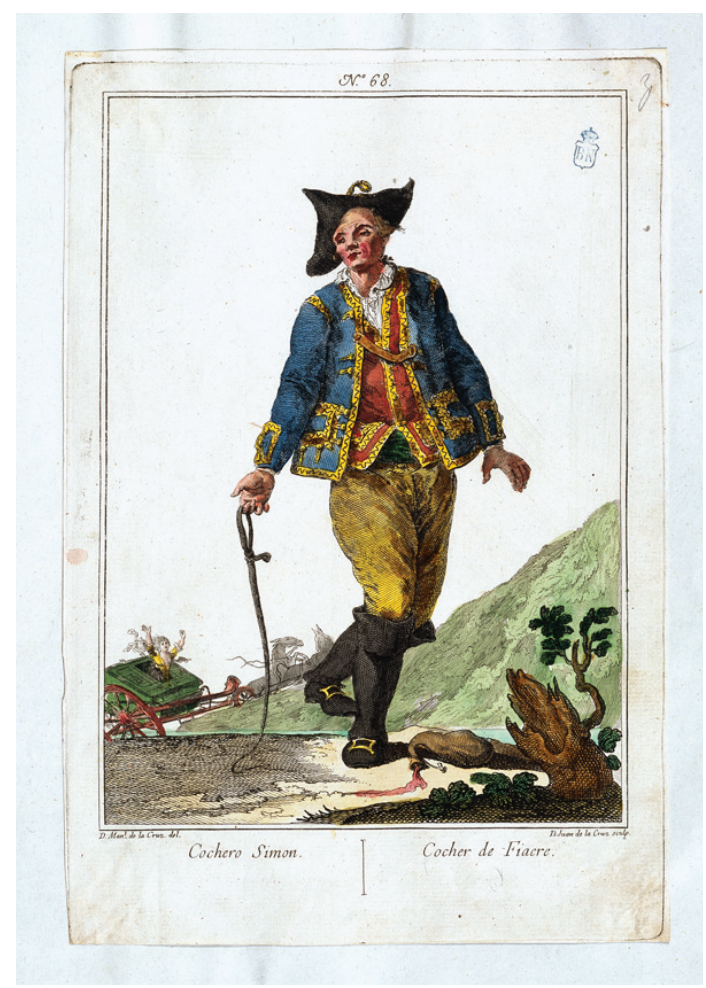

Figura 2. Manuel de la Cruz, "Cochero Simon”, 1785. Buril. 280 x 188 mms. Estampa 68 de Colección de Trajes de España tanto antiguos como modernos que comprehende todos los de sus dominios. Madrid, 1777-1790. BN: ER/3393 (68)

anónimo como consecuencia de la petición de dibujos originales que había publicitado en el grabado de la Portada y, ante tales dibujos, se cambiase la idea original y se optase por continuar con grabados más cercanos a los que en un principio parecía ser el espíritu de la obra.

Veinte días después de insertar la publicidad de los últimos grabados del sexto cuaderno, el 3 de abril de 1787, Juan de la Cruz anunciaría en la Gaceta los dos primeros grabados de lo que sería el séptimo y último de los cuadernos en donde se representaba a "un labrador y labradora de la Provincia de Betanzos" ${ }^{\text {"59 }}$. A partir de este último grabado la librería Copin, según la información de los anuncios de la Gaceta, dejará de distribuir la Colección de trajes que venderá Juan de la Cruz exclusivamente en su casa de la calle de la Cruz. Será este el momento en el que se rompa todo tipo de coherencia en la elección de los grabados. A finales de 1787 aparecerá anunciado el enigmático El autor a D. Benito en los siguiente términos: "estampa moderna ó figura antigua que el Duende de Madrid ha echado de menos en la coleccion de trages de España", texto que hace referencia a una crítica reci-

59 Gaceta de Madrid, 3.4.1787. 
bida por parte del diarista de El duende de Madrid Pedro Pablo de Trullench ${ }^{60}$. En mayo de 1788 se anuncia un grabado titulado El autor al público y que aparece referenciado en el anuncio de la Gaceta como "una petimetra que va por la calle" 61 y que no es más que un retrato de María Antonia Vallejo y Fernández, la Caramba. La nueva distribución no incrementó el número de ventas y, en el propio grabado, se incluye la siguiente advertencia:

En Francia y Alemania están copiando esta Colección sin Gracia alguna vendiendola en nuestros Puertos de Mar, esperamos, para poder continuarla que la Peninsula que la ha protexido no preferirá las contrahechas.

En julio aparecen dos representaciones taurinas -el Torero varilarguero y el Torero banderillero ${ }^{62}-\mathrm{y}$, en agosto ${ }^{63}$ y noviembre ${ }^{64}$ de ese mismo 1788 , dos representaciones de los trajes nacionales propuestos en el Discurso sobre el luxô de las señoras -la Nueva española y la Carolina o Para-todo-. Finalmente la Colección concluirá con la representación de dos bailes: Dos manchegos bailando seguidillas y Una gallega de Noya con un gallego de Tuy bailando la danza prima ${ }^{65}$ relacionada por Molina y Vega con la representación organizada por el Ayuntamiento de Madrid en el teatro del Príncipe donde se representó la composición de Ramón de la Cruz titulada Las provincias españolas unidas por el placer. Fin de fiesta, con que Madrid celebró la entrada del señor don Carlos IV en la corte con su esposa, la señora doña Luisa de Borbón y la jura del príncipe don Fernando ${ }^{66}$. La única coherencia que se puede encontrar en este último cuaderno está ya en relación con los temas teatrales...

Conviene detenerse en la gestación de una obra que en su conjunto tardó más de trece años en concluirse y que presenta, a lo largo de este dilatado tiempo, cambios de rumbo tan significativos. Pero, ¿qué se encontró quien pacientemente recopiló todos los grabados o los compró juntos tras 1790?, ¿qué discurso icónico desarrolló en su conjunto Juan de la Cruz en estos 82 grabados? Veámoslo utilizando como fuente de información las diferentes representaciones, las denominaciones que aparecen en las mismas y la fuente de información complementaria que proporcionan

60 Gaceta de Madrid, 22.12.1787. La estampa va acompañada de la siguiente cuarteta: "Ay vá tu Retrato Amigo, / Si de él, mi falta depende, / Por que no quiero que el Duende / Esté enfadado conmigo". Roque Pidal considera que representa al "celebre y gracioso Aldovera, "El Duende"” (PIDAL, Roque: Estampas y estamperos, Juan de la Cruz Cano, bosquejo biográfico artístico, Madrid, s.n., 1950, p. 21). Aunque no sería descartable que representase a Juan Aldobera el anuncio de la Gaceta (que se refiere explícitamente al "Duende de Madrid") relacionaría más bien el comentario con Pedro Pablo de Trullench, redactor del periódico que lleva ese nombre. Pedro Pablo de Trullench, junto a Joaquín Ezquerra, sería uno de los creadores del Memorial literario en 1784. No se ha podido localizar el comentario de Trullench en contra de la Colección de Juan de la Cruz.

61 Gaceta de Madrid, 6.5.1788.

62 Resulta significativo como, en la publicidad de la Gaceta, todavía se produce una división social entre los dos grabados en función del caballo. Así el Torero varilarguero se anuncia como "un caballero en plaza, varilarguero" mientras que el Torero banderillero se presenta como "un chulo vanderillero" (Gaceta de Madrid, 11.7.1788).

63 Gaceta de Madrid, 29.8.1788.

64 Gaceta de Madrid, 18.11.1788.

65 No se ha podido localizar ningún anuncio sobre estos dos últimos grabados.

66 Molina y Vega, op. cit. (nota 12), pp. 205-207. 
los anuncios en la Gaceta de Madrid. A través de ellas se intentarán establecer los criterios que Juan de la Cruz utiliza para identificar a sus personajes, es decir, cuáles son los elementos empleados que crean la identidad de lo representado.

Para ello, y dejando claro de antemano que nos encontramos ante diferentes niveles de identidad, se pueden establecer cuatro taxonomías: el género, la estratificación social, la ocupación y la ubicación geográfica. A través de estos cuatro elementos se recogerá la información que con vista a una posible identidad grupal, nos proporcionen los diferentes grabados. Ahora bien, hay que tener en cuenta que Juan de la Cruz privilegia algunas de estas clasificaciones sobre otras a la hora de crear identidades. Sin duda, los dos elementos identitarios más importantes serán el origen geográfico y la ocupación de los representados. Sobre estos dos elementos pivotarán las dos identificaciones básicas de la inmensa mayoría de las estampas. Y dentro de estos dos elementos, De la Cruz especificará de manera muy concreta. Así, cuando identifique a sus personajes por el origen geográfico se referirá a espacios físicos bien delimitados y bien determinados desde un punto de vista geográfico (ciudades y pueblos, comarcas, regiones, reinos e incluso espacios geográficos tan amplios como en el caso de la representación de las castas americanas) mientras que en el caso de las ocupaciones, los oficios seleccionados también serán fácilmente identificables por el espectador, si bien es verdad que en ocasiones se producirán algunos juegos de ocultamiento que podrían despistar al neófito que contemplase el conjunto. Serán estos dos elementos concretos los que marquen los procesos identitarios por parte del espectador.

A pesar de ello las clasificaciones de género y de estratificación social, secundarias desde un punto de vista de la identidad, también servirán para sacar a la luz algunas de las características generales de la Colección de trajes. Así, en cuanto a la división por género, se observa que en las estampas aparecen 97 personajes explicitados en los títulos de los grabados, al margen de algunos pocos más que aparecen representados en algunas de las impresiones. De estas 97 figuras, 47 son hombres mientras que 45 son mujeres y sólo aparecen representados cinco niños. Esta equiparación sexual determina uno de los objetivos de Juan de la Cruz, pues en muchas ocasiones se estampa en dos grabados que forman pareja tanto al hombre como a la mujer del tipo seleccionado y, sobre todo en los primeros cuadernos, tiene el cuidado de que el número de personajes masculinos y femeninos sea el mismo. Una verosímil representación de los diferentes trajes y la posibilidad de que los compradores fuesen tanto hombres como mujeres explicarían esta práctica igualdad en la representación de ambos sexos.

Si pasamos a analizar la estratificación social observable en el conjunto de representaciones, lo primero que llama la atención es la paradoja que presenta el resultado final de la colección con lo verbalizado cuando sale a la luz la Portada de la Colección a la altura de septiembre de 1778 -se debe recordar que ésta salió a la luz un año después del inicio de la propia Colección-. Según este grabado:

En el primer Volumen de esta Coleccion [...] saldrán los Trajes mas usuales de la Pleve del Reyno; y en el Segundo, los mas raros de la Nobleza de toda la Monarquia, estilados de dos Siglos á esta parte. 


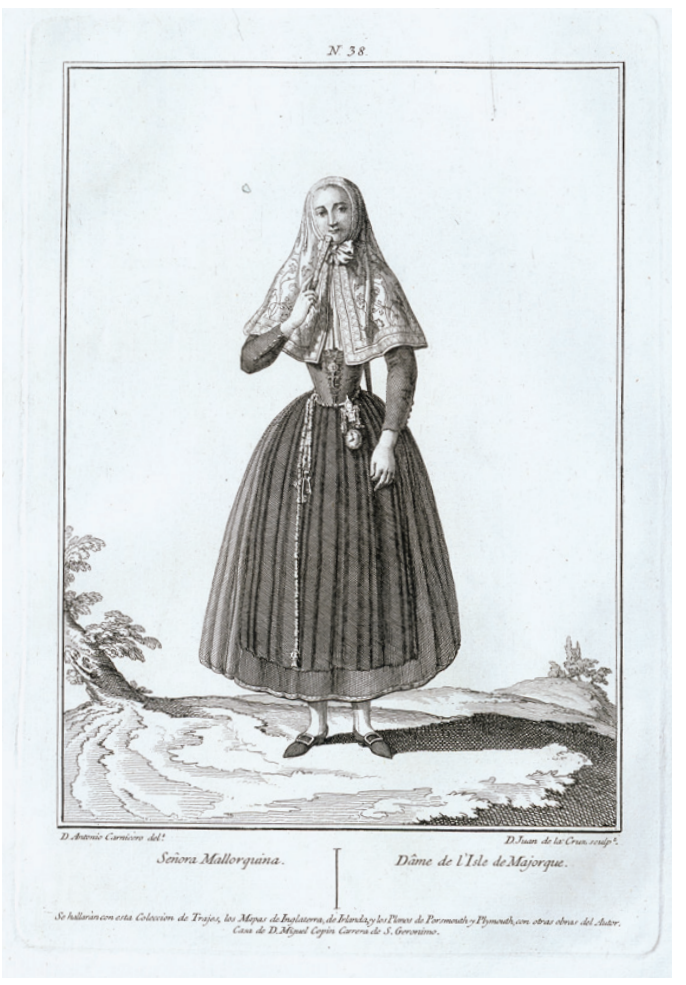

Figura 3. Antonio Carnicero, “Señora mallorquina”, 1780. Buril, 282 x191 mms. Estampa 38 de Colección de Trajes de España tanto antiguos como modernos que comprehende todos los de sus dominios, Madrid, 1777-1790. BN: ER/3393 (38)

Según esta información, en un principio la división básica sería precisamente la estratificación social entre plebe y nobleza, pero en la práctica la colección tomará otro rumbo en el que, por el contrario, esta división estamental está prácticamente ausente. Todo parece indicar que llegó un momento en el que a Juan de la Cruz no le interesó seguir esta división, lo cual puede justificar la ausencia de representaciones nobiliarias en los primeros cuadernos. A lo largo de la Colección sólo en un caso, en el ya tardío grabado 70 , se explicita el carácter nobiliario de la figura representada, una Viuda noble de las Islas Canarias ${ }^{67}$. En el resto de los casos que se presentan dudosos, la representación incide sobre aspectos como el origen geográfico (Andaluz, Canario de la Gran Canaria, Menorquina y Mahonés) o la

67 En los anuncios de la publicación de la Gaceta del grabado 77 se observa otro caso de denominación nobiliar aunque con unas características muy peculiares. En grabado titulado Torero varilarguero se anuncia como "caballero en plaza, varilarguero" en contraposición respecto a su pareja titulado Torero banderillero y anunciado como "chulo vanderillero" (Gaceta de Madrid, 11.7.1788). De manera más o menos inocente, De la Cruz está plasmando en la publicidad de su obra la dicotomía clásica en el mundo militar moderno, trasladado al ámbito taurino, entre el caballero en tanto que va a caballo y, por ende, es noble y el que va a pie y, por ello, no lo es. 
representación del tipismo como la Maja o Petimetra con manto en la Semana Santa en donde la condición noble es secundaria. Sólo en dos grabados más (el número 38 -Señora mallorquina (figura 3)- y el número 52 -Ciudadana de Bilbao-) se puede intuir la representación de dos damas de la baja nobleza. Sobre posibles representaciones de titulados y grandes, nada.

Tan interesante como la práctica ausencia de los nobles será la falta de representación del estamento eclesiástico. En el total de los 82 grabados sólo aparece representado un eclesiástico, el Abate del grabado 57 que, para más inri, aparece publicitado en la Gaceta como un simple "estudiante" ${ }^{68}$. Las tres acepciones que recoge el Diccionario de la Real Academia Española resultarán muy pertinentes para abordar al personaje. Son las siguientes:

1. m. Eclesiástico de órdenes menores, y a veces simple tonsurado, que solía vestir traje clerical a la romana.

2. m. Presbítero extranjero, especialmente francés o italiano, y también eclesiástico español que ha residido mucho tiempo en Francia o Italia.

3. m. Clérigo dieciochesco frívolo y cortesano. ${ }^{69}$

Un eclesiástico con órdenes menores, con influencias extranjeras, frívolo y cortesano. Una figura central en cierto mundo urbano dieciochesco pero, sin duda, poco representativo de lo que cualquiera de sus coetáneos pudiera identificar como el estamento eclesiástico.

La división estamental no es la única que actúa en la taxonomía de estratificación social presente en la Colección. En la primera mitad del sexto cuaderno (grabados 61-66) Juan de la Cruz decide plasmar los diferentes trajes de las castas americanas. A lo largo de seis grabados, en las correspondientes tres entregas, se suceden las denominaciones de "español", "indio", "mestizo", "collote", "negro", "mulato", "morisco", "chamizo" y "albino". Sin duda, una selección bastante representativa del mundo castizo americano. Aunque finalmente no plasma los 16 grabados que anuncia al inicio de este cuaderno, en la Gaceta del 22 de junio de 1784, la aparición de estos seis grabados, si bien no es totalmente incongruente con el resto de la serie pues ya había representado a un Gíbaro de la isla de Puerto Rico -grabado número 29-, a una India del Perú -número 35- e incluso a una Esclava de Puerto Rico ${ }^{70}$-número 30 -, sí supone un cambio en la selección de los tipos que altera profundamente el conjunto, incluso a nivel compositivo, pues el autor se ve obligado a representar a tres figuras en cada uno de los grabados. Nos encontramos ante un conjunto de estampas independientes que se relacionarían con la tradición de la pintura de castas en América, pujante en el siglo XVIII ${ }^{71}$, y cuya elección, desde nuestro punto de vista,

68 Gaceta de Madrid, 27.2.1784

69 Real Academia Española: Diccionario de la lengua española, Madrid, 2001, 22a edición, p. 3.

70 La representación de la esclava puertorriqueña, en tanto que esclava, se vincularía con una discriminación legal pero no castiza. Sin embargo, el tono oscuro de su piel, sus rasgos fisonómicos y el hecho de que haga pareja con el grabado del gíbaro vincula el grabado con la diferenciación castiza.

71 La llamada "pintura de castas" es una de las manifestaciones más originales e interesantes del arte colonial americano. Relacionada con cuestiones raciales, identitarias, sociales y antropológicas, ha pasado 
fue consecuencia de un intento por parte de Juan de la Cruz, en la línea general de la Colección, de allegar a la misma una nueva influencia que estaba teniendo gran éxito en el mundo americano y que por su "tipismo" podía reportarle beneficios económicos además de mostrar una faceta sorprendente y poco conocida en la Corte del imaginario visual de la Monarquía.

La prácticamente nula representación de los estamentos privilegiados denota uno de las características más "modernas" de la Colección de trajes. Aunque los datos de los que disponemos no nos permiten saberlo con certeza, nada nos indica que el autor tuviera algún interés en representar al estamento eclesiástico mientras que, aunque finalmente no se llevó a cabo, al menos en un principio sí parece que pretendiese representar los vestidos "mas raros de la Nobleza de toda la Monarquia". Bien es cierto que a lo largo de los años en ninguno de los cambios temáticos que fue introduciendo en la Colección se optó por la representación de dichos trajes. De manera a todas luces consciente, Juan de la Cruz decidió excluir de su representación de la vestimenta de "España y sus dominios" a los estamentos legalmente privilegiados. Por ahora, quedémonos con este dato.

Así, la inmensa mayoría de los trajes representados pertenecían explícitamente -a través de las ocupaciones reseñadas en los títulos- a miembros del estamento no privilegiado o eran identificados en relación con una localidad o región, y su representación icónica no denotaba la pertenencia a la nobleza. En este conjunto de no privilegiados es en donde hay que ubicar la primera de las dos tipologías que para De la Cruz sí resultaban relevantes para la determinación de una identidad: la ocupacional. Ahora bien, la identificación por la ocupación, básica en la serie, contiene a la postre una gran cantidad de variantes ocasionadas por multitud de influencias, desde los intereses del autor, hasta el material de origen que le ofrecen los dibujos y dibujantes que le sirven como base, pasando por las influencias generales de muchos de los grabados o las contingencias puntuales en la publicación de las estampas.

Un número bastante significativo de los grabados -33 de los 82 , lo que supondría un $40 \%$ del total, que subiría a un $45 \%$ si no se contabilizan los seis grabados de la pintura de casta y los dos sobre los trajes nacionales ${ }^{72}$-, son identificados desde el propio título con las ocupaciones de los tipos propuestos, y en muchas otras ocasiones la simple visión de la imagen proporciona datos irrefutables de las actividades profesionales de los representados. Además, las identificaciones geográficas del título camuflan representaciones laborales como se observa, por ejemplo, en el caso del grabado 19 en donde la Maragata aparece con sus pertrechos para hilar.

No siempre ocurre esto. En otras ocasiones la vinculación entre la localidad geográfica y la labor profesional es imposible. Así, en los grabados 23 y 24 que representan a una pareja charra de Salamanca, las figuras aparecen mirando al frente y

relativamente desapercibida en los análisis del arte colonial hasta los últimos años. Se pueden citar los siguientes trabajos: García SaIz, Ma Concepción: The Castes: A Genre of Mexican Painting, Milán, Olivetti, 1989; KATZEW, Ilona: La pintura de castas: representaciones raciales en el México del siglo XVIII, Madrid, Turner, 2004, y Carrera, Magalie M.: Imagining Identity in New Spain: Race, Lineage, and the Colonial Body in Portraiture and Casta Paintings, Austin, Tesis doctoral, 2003.

72 En siguientes porcentajes aportados en esta apartado se indicarán los dos datos al considerarse poco significativos los datos generales por las características propias de los grabados reseñados. 
posando para un retrato con sus mejores galas. Por último, en algunos casos, esta vinculación, como ya hemos apuntado anteriormente, se completaría en los grabados en los que la ocupación y el origen geográfico se solapan, como ocurre con el caso de la representación del Chorizero (grabado 13), que puede ser interpretado por el observador tanto por su labor de vendedor de chorizos como por su supuesta procedencia de localidades extremeñas.

Si reunimos la información aportada por el título de la estampa, el grabado en sí mismo y las noticias de la Gaceta, podremos concluir que de las 82 estampas, en 58 de ellas -un 71\% del total y un 78\% con las ocho eliminaciones realizadas- se representan a personas que trabajan, lo cual solo es relativamente sorprendente tras la comprobación anterior de la práctica ausencia de representaciones de estamentos privilegiados ${ }^{73}$.

Pero ¿qué labores se representan? y ¿cómo se representan? Para contestar a la primera pregunta puede resultar interesante intentar clasificar por sectores económicos las diferentes actividades productivas. Así, de las 58 ocupaciones laborales, la mitad de ellas, 29, corresponderían a actividades del sector primario, mientras que en 25 ocasiones se representarían actividades del sector terciario (un 41\%) y solamente en cuatro estampas aparecen actividades artesanales (un 9\%). Más allá de una conclusión apresurada sobre un reflejo de la escasa pujanza de la actividad artesanal en la Monarquía, realmente en la explicación de estos porcentajes se deben mezclar las fuentes de inspiración de los grabadores, el mercado al que iban dirigidas las estampas y los condicionantes geográficos de la serie.

Como ya observó Valeriano Bozal, el carácter novedoso de la Colección provocará que Juan de la Cruz recoja diferentes influencias para su realización, y una de ellas son las exitosas series de grabados de vendedores de las grandes ciudades, con una larga tradición entre los grabadores de Francia, donde nuestro autor se forma a mediados de siglo ${ }^{74} \mathrm{y}$ de donde también derivarán las mejores representaciones hispanas como, entre otras, la serie de Miguel Gamborino Gritos de Madrid ${ }^{75}$.

Ahora bien, las abundantes representaciones del sector terciario no sólo derivarán de estas influencias. Por decirlo de manera obvia, las series de vendedores influyen porque Juan de la Cruz les proporciona un significado determinado. Si observamos la colocación de este tipo de grabados a lo largo de la Colección nos daremos cuenta de que son claramente predominantes en los dos primeros cuadernos, apareciendo puntualmente en los posteriores. Se ofrecen, en fin, como la presentación de la serie, observándose por parte del grabador un deseo de vincular las representaciones con sus posibles compradores, que no eran otros que las clases mesocráticas de la Corte y

73 Este porcentaje aumentaría si se incluyesen las representaciones de los grabados 31 y 32 de los arrendadores de la huerta de Murcia pues aunque, por el título, se han incluido entre los ociosos, la representación del grabado relacionaría más a los personajes con trabajadores que con desocupados.

74 Bozal, Valeriano: «Juan de la Cruz Cano y Olmedilla y su Colección de trajes de España», en CRUZ Cano y Holmedilla, Juan de la: Colección de trajes de España tanto antiguos como modernos, Madrid, Turner, 1981, pp. 11-15 (2 ${ }^{\text {a }}$ edición, 1988), y, con ligeros retoques, en: BozaL, Valeriano: «La estampa popular en el siglo XVIII» en Carrete Parrondo, Juan, Checa Cremades, Fernando y Bozal, Valeriano: El grabado en España (siglos XV al XVIII) en Summa Artis. Historia general del arte, vol. XXXI, Madrid, Espasa-Calpe, 1987, pp. 670-677.

75 Gamborino, Miguel: Los gritos de Madrid, Madrid, Imprenta Real, 1817. 
de las principales ciudades de la Península. De la Cruz tenía que ofrecer, sobre todo al principio de la Colección, imágenes cercanas y conocidas de sus consumidores y qué mejor que un ciego tocando su instrumento, una vendedora de la Gaceta o de naranjas, dos expendedores de agua o la representación de la autoridad en manos de un alguacil... ${ }^{76}$ Así, los materiales icónicos reutilizados adquirían, a través del tipismo costumbrista del que también habla Bozal, un nuevo significado eminentemente comercial $^{77}$.

A estos dos factores hay que añadir el de las localizaciones geográficas elegidas que resultan esclarecedoras para las estampas agrícolas y ganaderas. En pos de una lógica variedad geográfica y de una representación espacial variada y original, Juan de la Cruz elegirá trajes de diferentes localidades o regiones que, en un mundo fundamentalmente agrario como el hispano a finales del siglo XVIII, no podían reflejar otra cosa que el mundo campesino. Así la sucesión de chesos, charros, roncaleses o jebos no podían dejar de reflejar el entorno rural del que procedían, por más que también se incluyesen, siempre por simple lógica estadística, personajes como el Artesonero abulense o el Maragato leonés junto a un más variado conjunto de representaciones de las Islas Baleares que podía llegar a incluir peculiaridades como el Marinero mallorquín -único representante de la actividad pesquera- o el Traginero mallorquín. Hay que constatar que la determinación o no en el título de las ocupaciones profesionales de los representados dependería en la mayoría de las ocasiones del mayor o menor número de grabados dedicados a la zona geográfica en cuestión. Por contra, la determinación de los tipos vendría determinada por el poco desarrollo artesanal que se observa en la economía hispana del siglo XVIII.

Parece conveniente realizar un último apunte en cuanto a las representaciones laborales, que no sería otro que la constatación de la importante presencia del concepto del ocio en la serie, derivado tanto de los objetivos últimos del autor como de los gustos del público. Aunque muchos grabados, como hemos visto, identifican a los personajes por su trabajo, en muy pocas ocasiones se representa la realización efectiva del mismo y cuando se representa al personaje trabajando mayoritariamente se relaciona esta labor con elementos de diversión.

La aparición del elemento ocioso en los grabados se manifiesta a través de diversas estrategias. De forma evidente, muchos grabados (los cuatro que representan el mundo taurino, los dos del mundo teatral e, incluso, el Ciego jacarero que abre la serie) representan a gente cuyo trabajo es entretener a los demás, lo que puede ser fácilmente explicable por la coyuntura personal de Juan de la Cruz y sus estrechas relaciones con el mundo del teatro o el éxito de los grabados taurinos. Pero hay más. En otro grupo de grabados se representan directamente figuras urbanas que no trabajan, como en el caso de la Maja o personajes de su entorno (el Abate, la Modista, el Peluquero)

76 Serán 16 los grabados que cumplan estas características: Ciego jacarero, Gazetera, Naranjera, El agua de cebada, Barbero majo, dando música, Aguador de compra, Alguacil, Chorizero, Verdulera, Naranjero murciano, Criada, Azeitero, Modista, Peluquero y Cochero Simón.

77 Las representaciones del sector terciario se completarían con aportaciones coyunturales como las estampas teatrales (las tituladas El autor a D. Benito y El autor al público -ésta, por otra parte, anunciada en la Gaceta como "petimetra que va por la calle"-) que se vincularían con las tres estampas conservadas del Quaderno de trages del teatro y las atractivas representaciones taurinas de moda en el momento, tanto los retratos de Pedro Romero y Joaquin Costillares como las estampas del Torero varilarguero y del Torero banderillero. 
llegándose incluso, en el caso del Barbero majo, dando musica, a representar en esta línea ociosa y típicamente urbana del que sólo sabemos su profesión por el título del grabado. En otras ocasiones los campesinos se divierten, como en las dos últimas estampas de la Colección (Dos manchegos bailando seguidillas y Una gallega de Noya con un gallego de Tuy bailando la danza prima). Pero lo que resulta más significativo es la representación del mundo rural, simbolizada en la doble representación del pagés mallorquín (grabados números 37 y 47) en una ocasión representado con su traje habitual y, en la otra, vestido, literalmente, «en día de fiesta». Un simple visionado de la Colección nos permite comprobar la idealización de las figuras campesinas, que en la mayoría de las ocasiones también van vestidos, aunque no se mencione en los títulos, de una manera excepcional (sirvan los ejemplos, entre otros, de la Roncalesa o de la Chesa). No hay una representación realista de los atuendos habituales para efectuar un trabajo, como queda claramente de manifiesto en el primer grabado del Ciego jacarero. Las características de la serie hacían impensable cualquier tipo de representación realista de los trabajos de las clases subalternas dado que los potenciales consumidores, la mesocracia ciudadana, probablemente los hubiera rechazado. En el fondo, no se pretendía otra cosa que representar, desde la idealización de lo que se podría denominar como el "vestido limpio" y las "mejores galas", una variedad de vestidos que resultasen agradables para los posibles compradores. Esta idealización proporciona al conjunto un alejamiento del mundo laboral, que cede su puesto a superficialidad del entretenimiento más o menos burgués.

El otro elemento identitario básico mostrado por los grabados, sus títulos y la publicidad que se hizo de ellos en la Gaceta, está en relación con la ubicación geográfica de los tipos representados. Este aspecto superpone dos aspectos diferenciados: el carácter urbano o rural de la representación y la posible localización geográfica de la misma. Aunque de manera superficial pudiera parecer que el segundo elemento sería más significativo para la caracterización de las estampas en cuanto muchas de ellas incluyen dentro de su título el origen geográfico de traje representado, en realidad consideramos que el primer elemento -el carácter rural o urbano del grabado- tendrá, finalmente, mayor importancia explicativa. Tratemos en primer lugar el sorprendente elevado porcentaje de tipos urbanos representados en una monarquía como la hispana a finales del siglo XVIII, profundamente ruralizada desde un punto de vista demográfico. En sesenta y nueve de las ochenta y dos estampas publicadas (un $84,1 \%$ ) es posible determinar el carácter ciudadano o campestre de la representación dividiéndose, de manera sorprendente, a la par el número de figuras estampadas. Así, 35 de estas 69 (un 50,7\%) pertenecerán al mundo urbano mientras que 34 (un 49,3\%) inciden en aspectos rurales.

Estos porcentajes globales esconden algunos problemas de interpretación que, aunque no son muy destacables, deben ser comentados pormenorizadamente. Muchos de los empleos ciudadanos tenían una vertiente rural, presentando ante el espectador un posible doble significado. Este es el caso, por ejemplo, de la Naranjera o el Chorizero que, aunque representaban a vendedores especializados del ámbito urbano, también podían ser interpretados como representantes geográficos de Valencia o Extremadura, respectivamente. De igual modo, el Andaluz, contabilizado entre los trece grabados indeterminados, puede ser leído -como se hará en otras colecciones de trajes pos- 
teriores- como el prototipo del contrabandista, que mantendría un carácter híbrido entre la ciudad y el campo. Estas dificultades taxonómicas pueden apreciarse en otros tipos -tales como el "Catalán" y la "Catalana" que tampoco han sido contabilizados en ninguno de los dos grupos- pero no alterarían profundamente una visión en donde el elemento urbano esta sobrerrepresentado en relación con el porcentaje real en la Monarquía de finales del siglo XVIII.

Aunque la explicación de esta paridad compositiva derive fundamentalmente de las propias características de los modelos elegidos (representaciones de modelos teatrales, influencias de las representaciones de los grabados de oficios franceses y de los grabados de tauromaquia tan en boga en el momento), tal elección, a su vez, es altamente significativa en sí, tanto por parte de los deseos de Juan de la Cruz en la elección de lo representable, como de sus compradores en lo que deseaban adquirir.

Un último punto conviene aclarar respecto a las representaciones de prototipos urbanos que, a su vez, nos permitirá enlazar con la clasificación geográfica a nivel local, regional o regnícola. Más allá de las representaciones teatrales o de figuras relacionadas con la fiesta taurina, se observa un tipo de representación de los trajes urbanos, absolutamente mayoritario en el primer cuaderno, en donde se mezclan los diferentes oficios subalternos (Ciego jacerero, Gazetera, etc.) con representaciones de las clases mesocráticas "a la moda", por otra parte nunca mejor dicho: Maja, Petimetra con manto en la Semana Santa, Modista, Abate... Aparecen así los personajes de mayor actualidad en los cambios sociales urbanos durante la segunda mitad del siglo XVIII, enlazados con las obras teatrales de los Moratín o del propio Ramón de la Cruz, acosados por los moralistas y los autores conservadores y apreciados por los modernizadores y los autores más europeístas.

Este doble tipo de representaciones están claramente inspiradas, como no podía ser de otra manera, en la realidad madrileña de la corte de finales del siglo XVIII, aunque no aparece especificada su ubicación geográfica -fuera de estar en un ambiente urbano- ni en los títulos ni en ninguna de la información proporcionada por la Gaceta. Este es el motivo por el que no aparecerán, posteriormente, como localizados de manera concreta en ningún punto de la Monarquía, pero no hay que olvidar que tanto el grabador como el comprador de estas estampas las ubicaban naturalmente en el contexto madrileño como capital de la Monarquía. Esta ambigüedad geográfica explicará, por una parte, la escasa representación de Madrid y la Corte en las ubicaciones que se analizarán a continuación y, por otra, servirá de ejemplo de los titubeos sobre el modo de presentación de la colección, resuelto en publicaciones posteriores a través de una estricta división de las láminas basándose en la diversidad geográfica de los representados pues ya se consideraba necesario fijar desde un punto de vista geográfico la diversidad de los trajes representados.

Si, por último, pasamos ahora al análisis geográfico de la ubicación de las estampas, lo primero que llama la atención es la diversidad de la localización. En los grabados la definición geográfica, cuando aparece, varía desde un espacio geográfico muy pequeño ("el partido de Ávila" o el valle del Roncal en Navarra) hasta la localización de la figura mediante la denominación de un reino (Cataluña, por ejemplo) e, incluso, la implícita designación de las Indias cuando se representan las diferentes muestras de pintura de castas. No parece, por estas indecisiones, que el sentido primordial de 
las divisiones geográficas derive de un intento consciente de clasificación de las imágenes basándose en criterios topográficos sino, más bien, tales referencias servirían como identificadores individuales de los diferentes trajes considerando secundario, o sobreentendido por los compradores, la posible taxonomía de carácter local, regional o regnícola.

De las ochenta y dos estampas dadas a la luz por Juan de la Cruz, en 56 casos $(68,3 \%)$ se pueden identificar ciertos orígenes geográficos, mientras que en las 26 restantes la localización geográfica puede llegar a ser dudosa o resultar intrascendente. Si dividimos por reinos estos 56 grabados, en 35 -un 62,5\%- de los mismos se identifican personajes castellanos (teniendo en cuenta que diez de estas 35 representaciones corresponden a laminas ubicadas en América), en 19 casos -un 33,9\%las representaciones pertenecen al territorio de la Corona de Aragón y en sólo dos imágenes -un 3,6\%- las figuras se sitúan en el Reino de Navarra. Estos porcentajes generales, en realidad, resultan poco significativos pues, como ya se ha apreciado, el propio desarrollo de las impresiones durante más de diez años marcará una serie de fluctuaciones en los objetivos de la obra que la desvirtuarán desde un punto de vista de la representatividad geográfica. Así, el cuaderno de representaciones de trajes de las Islas Baleares provocará una mayor representación del Reino de Mallorca con doce trajes (un 21,4\%) que no puede explicarse por la importancia en sí de tal reino sino, como ya se ha dicho, por la popularidad alcanzada en la guerra contra Gran Bretaña. Similar caso sería el de los trajes americanos, en donde seis de sus diez representaciones se relacionan con la decisión de Cruz de representar, en un primer momento en 16 imágenes, algunas de las pinturas de castas indianas. La propia evolución de la publicación de la obra invalida cualquier explicación distributiva en función de criterios exclusivamente geográficos a pesar de que, curiosamente, el resultado final proporciona unos datos en donde se representan, más allá del porcentaje, la inmensa mayoría de las posesiones de la Monarquía, salvo los territorios filipinos y del norte de África.

Lo verdaderamente significativo del uso de la ubicación geográfica de los trajes no derivará de su utilización para una posible ordenación de los grabados -salvo en los dos casos especiales relacionados con los grabados de las Islas Baleares y las representaciones de castas americanas- con fines taxonómicos que pudiera fácilmente interpretarse como un deseo de abarcar el mayor número posible de localidades y regiones, como pasará en futuras colecciones. La determinación especial en este caso se mueve exclusivamente en el plano de la identificación individualizada de las estampas - generalmente en parejas de hombre y mujer-. Juan de la Cruz no pretende con esta localización abarcar más o menos la totalidad del territorio de la Monarquía, aunque en la práctica lo consiga, sino, más bien, identificar a prototipos particulares.

A diferencia de colecciones de grabados de trajes posteriores, como por ejemplo la Colección general de trajes de Antonio Rodríguez ${ }^{78}$, Juan de la Cruz no dividirá la suya en diferentes apartados geográficos, lo que dificultaría al espectador vincular la Colección con una representación exhaustiva de los trajes de las diferentes provincias

78 Coleccion general de los trajes que en la actualidad se usan en España: principiada en el año 1801, Madrid, s.n., 1801. 
españolas. La falta de ordenación de los grabados en esta obra, además de proporcionar una mayor libertad de elección (que sería muy útil al grabador cuando quisiera incorporar nuevas temáticas) y de no verse obligado a forzar la inclusión de determinadas estampas no definidas geográficamente (oficios urbanos, majas y petimetras...) en alguna localidad (como le ocurre a Rodríguez sobre todo en las estampas dedicadas a la ciudad de Madrid y de Cádiz), le permitirá centrar el interés geográfico de sus elecciones más en las particularidades locales que pudiese considerar dignas de representación que en una hipotética y nada desarrollada idea de representación geográfica general.

Nos encontramos así con una colección que, más allá de los vaivenes que su larga gestación propiciará y de sobrerrepresentaciones ya explicadas individualmente (presencia de artistas teatrales o de representaciones taurinas, elecciones puntuales de trajes de las Islas Baleares, etc.), presentará unas características temáticas generales más coherentes de lo que a primera vista pudiera suponerse: la representación de hombres y mujeres es paritaria, la ausencia de representaciones de nobles y eclesiásticos es altamente significativa, el elemento urbano está representado muy por encima de los porcentajes reales de su población mientras que, aunque la influencia de las representaciones de los oficios urbanos es alta, el elemento del ocio -a través las estampas teatrales, taurinas o de elementos ociosos de la sociedad urbana- juega un papel muy importante en el conjunto de la Colección.

Otra fuente, en este caso podríamos decir que "negativa", nos informará de las intenciones del autor en el caso de la Colección que estamos analizando. En la Biblioteca Nacional de Madrid se conservan veinticuatro dibujos ${ }^{79}$ que según las fuentes consultadas se realizarían para servir de base a futuros grabados a publicar pero que, sin embargo, nunca vieron la luz como grabados. Estos dibujos están todos firmados por Manuel de la Cruz Cano -aunque en tres de ellos también colaborará la mano de otro miembro de la familia, Narciso de la $\mathrm{Cruz}^{80}$ y parece bastante probable que fueran realizados durante los primeros años de publicación de la obra ${ }^{81}$. Intentar explicar las causas por las que fueron rechazados puede resultar interesante para comprender los objetivos últimos de Juan de la Cruz en los que sí consideró oportuno estampar. Y para ello nada mejor que conjeturar sobre los posibles motivos individuales por los que fueron desestimados los diferentes dibujos -dejando a un lado las posibles

79 Se ha conservado también en el gabinete de dibujos de la Biblioteca Nacional de Madrid otro, titulado [Caballeros de las Órdenes Militares] (BN: DIB/14/4/12) catalogado por Barcia como perteneciente a este conjunto de dibujos que no se estamparon dentro de la Colección de trajes de España. Sin embargo, se ha decidido no incluirlo entre la relación de los dibujos no estampados pues las características formales del dibujo - una representación en grupo de cuatro caballeros de las órdenes militares de Santiago, Calatrava, Alcántara y Montesa- no parece que se correspondan con los otros dibujos de esta Colección.

80 Corresponden a los que llevan por título: Ciego de la Gayta y las Furriñas, El Abaniquero y Chinita, Comico ridiculo en el sainete de Manolo.

81 Esta idea no deja de ser una hipótesis sin apoyatura documental. Parece factible que fueran realizados por Manuel de la Cruz al principio de la Colección cuando fue él quien se ocupó casi exclusivamente de proporcionar dibujos originales a Juan de la Cruz para su grabado. Además, temáticamente, la mayoría de los dibujos -salvo los de tema teatral que deberían vincularse con el Quaderno de trages de teatro cuyos primeros grabados salieron a luz en 1783- corresponden a temáticas similares en los dibujos de Manuel de la Cruz que sí consiguieron convertirse en grabados (oficios de la Corte, majos, representaciones de diversas autoridades y láminas de tauromaquia) y que salieron en los primeros cuadernos de la colección. 
dificultades técnicas o una valoración negativa sobre su calidad que parece poco probable- para descubrir, finalmente, que la inclusión de estos dibujos descompensaría los cambiantes objetivos generales del autor.

Un rápido repaso a los dibujos conservados revela tres de los prototipos ya presentes en la Colección de trajes estampada: variantes de las escenas urbanas de la Corte -oficios, vestimentas peculiares de autoridades y ropajes de majos ociosos-, retratos teatrales y escenas de tauromaquia. Si buscamos posibles justificaciones para estos descartes se puede considerar, si empezamos por las escenas de tauromaquia, que las cuatro presentes en la Colección podrían ser suficientes quedando las dos versiones dibujadas para una posible reutilización para otros fines ${ }^{82}$. Por lo que respecta a las figuras teatrales su exclusión podría venir determinada por idénticos motivos de exceso innecesario uniéndose a ellos la posibilidad, apuntada en 1783, de la realización de un cuaderno específico sobre trajes teatrales que parece que no tuvo continuidad ${ }^{83}$.

La exclusión del grupo más importante de láminas, diecinueve, con diferentes representaciones urbanas pasarían por la repetición tanto de tipos que ya figuraban en la Colección -en el caso, por ejemplo, de los tres dibujos sobre aguadores ${ }^{84} \mathrm{o}$ los dos de majos ${ }^{85} \mathrm{o}$ las representaciones del ciego ${ }^{86}$, el alguacil ${ }^{87} \mathrm{o}$ el abate ${ }^{88}$, , como de ocupaciones ya suficientemente estampadas ${ }^{89}$-vendedores ${ }^{90} \mathrm{o}$ músicos callejeros ${ }^{91}-$; por la decisión de no mostrar la parte más miserable de la sociedad urbana -en el caso del Hospiciano que sirve para acompañar en los entierros ${ }^{92}-$; o por evitar sobrecargar la colección con vestimentas poco significativas, como el Mazero de la Villa de Madrid que ba en las funciones de los Consejos ${ }^{93}$. Un caso significativo será el dibujo titulado Traje de Camarista de Castilla ${ }^{94}$ (figura 4) que representaba a los jueces más importantes de la Monarquía. Es difícil intuir las causas por las que este dibujo no fue elegido, pero quizá pueda pasar por su vinculación al estamento nobiliario y a la parte más tradicionalista de los servidores del monarca.

82 Torero con caballo, y bara larga (BN: DIB/14/4/35) y Torero noble con el rexon, y Chulos (BN: $\mathrm{DIB} / 14 / 4 / 34)$.

83 Chinita, Comico ridiculo en el sainete de Manolo (BN: DIB/14/4/32), Doña Maria Josepha Huerta dama de la Compañia de los Chorizos (BN: DIB/14/4/40), [Retrato de la actriz Polonia Rochel] (BN: DIB/14/4/38) y [Retrato de Josefa Carreras] (BN: DIB/14/4/39).

84 Aguador comun de todas las Casas, llamados de la Burra (BN: DIB/14/4/25), Aguador con su Burra al ordinario (BN: DIB/14/4/42) y Aguador de Zevada y su carro (BN: DIB 14/4/41).

85 Un Majo en Bravo (BN: DIB/14/4/26) y Un majo jaquetón (BN: DIB/14/4/23). Por otra parte el dibujo titulado Español conforme se pasea con su capa y sombrero (BN: DIB/14/4/43) no deja de ser la representación prototípica de otro representante de esta sociedad cortesana, la del embozado.

86 Ciego de la Gayta y las Furriñas (BN: DIB/14/4/27).

87 Aguacil segun sale en las Fiestas de los Toros (BN: DIB/14/4/37).

88 Abate en traje de clerigo regular (BN: DIB/14/4/10).

89 Solo el dibujo titulado El Abaniquero (BN: DIB/14/4/33) sea el único en donde resulte difícil justificar su ausencia en la colección, pues es lo suficientemente pintoresco.

90 Ay pay-tuya, que bender (BN: DIB/14/4/30), Yerro Viejo, quien bende (BN: DIB/14/4/28) y Bollero que bende Elefantes de Leche (BN: DIB/14/4/29).

91 Un Hombre tocando la Zambonba (BN: DIB/14/4/44) y Un trompetero, que sirve en las Procesiones de la Semana Santa (BN: DIB/14/4/9).

92 BN: DIB/14/4/24.

93 BN: DIB/14/4/31.

94 BN: DIB/14/4/22. 


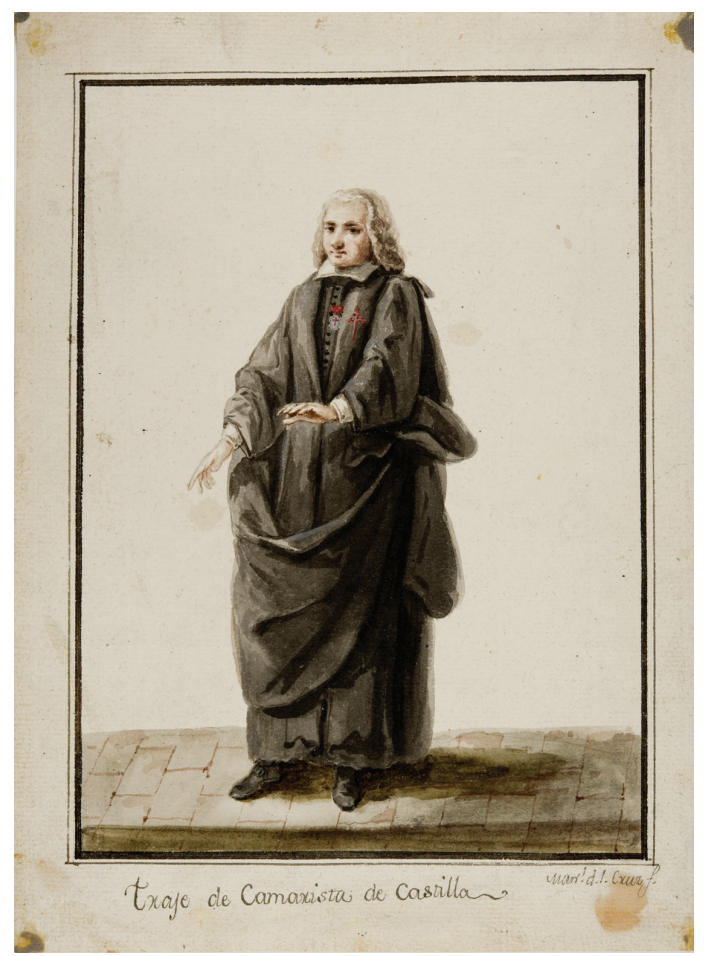

Figura 4. Manuel de la Cruz, Traje de Camarista de Castilla, s.f. Dibujo. 240 x 178 mms. BN: DIB/14/4/22

Estas explicaciones individualizadas deben completarse con explicaciones generales relacionadas con las intenciones últimas de Juan de la Cruz. Si observamos en términos generales los dibujos no grabados, nos daremos cuenta de que la inmensa mayoría de ellos representan hombres -sólo hay tres representaciones femeninas y significativamente son de tres actrices-, en todos los casos se representan personajes del entorno de la Corte y del ámbito urbano y mayoritariamente en actividades productivas. En términos generales haberlos incluido desnivelaría sustancialmente el frágil equilibrio alcanzado en la elección final de lo estampado.

Siendo de antemano conscientes de que cuatro factores importantes (el carácter pionero de la Colección en la Monarquía Hispánica, la gran extensión temporal de su publicación, el carácter marcadamente mercantil de la edición y la trascendental influencia coyuntural y personal de las elecciones de trajes) limitan poderosamente las interpretaciones sobre los objetivos generales, más allá de los comerciales, de Juan de la Cruz tomando la obra en su conjunto, también se ha podido dilucidar que sí se pueden atisbar algunas ideas generales a trasmitir a través de la selección de piezas: ausencia de los estamentos privilegiados, desmesurada representación de elementos urbanos mezclando los oficios populares y los ocios mesocráticos, equilibro en cuanto a la representación sexual y amplia muestra no proporcional de la mayor parte de los territorios de la Monarquía. 
Es el momento de reflexionar sobre la posible utilización identitaria del concepto de España que se repite machaconamente a lo largo de toda la publicidad de la Gaceta de Madrid. Desde el primer anuncio se pretenderá que se identifique a la nueva colección como "Colección de trages de España", titulo que se repetirá continuamente desde en todos los anuncios desde el 2 de septiembre de 1777 hasta el número del 23 de abril de 1784, incluso tras la publicación de la Portada a la altura de septiembre de 1778 cuando se anunciaban las estampas 25 y 26 . El comprador de las primeras veinticuatro láminas, casi una tercera parte del total final de la colección, sólo conocía esta denominación para definir unas estampas que se habían centrado en la representación de oficios y ocios de la Corte y algunos trajes campesinos de la Península.

Evidentemente, la publicación de la Portada le proporcionaría nueva información. En una "advertencia" de la que ya hemos hablado se le comunicaba que saldrían dos tomos, uno dedicado a los trajes "de la pleve" y otro a "los mas raros de la Nobleza de toda la Monarquía, estilados de dos Siglos á esta parte". El título de la obra especificaba que se grabarían 192 estampas divididas en dos tomos divididos estamentalmente y que iba a tener, por lo menos en las representaciones nobiliarias, un carácter también histórico.

El calificativo de "toda la Monarquía" aplicado, eso sí, a los trajes de la nobleza en la nota aclaratoria, completaba una información de mucho interés que se anunciaba en el título de la obra: la "Coleccion de trages de España" se había convertido en la "Coleccion de trajes de España, tanto antiguos como modernos, Que comprehende todos los de sus Dominios". La Colección se expandía temporal y, quizá para alguno de sus compradores, espacialmente. De lo que no había duda es que Juan de la Cruz había considerado oportuno informar a sus compradores de esta expansión espacial. La confusión entre España y la Monarquía era posible. Inmediatamente, sólo dos entregas después y probablemente aprovechando la estancia de Luis Paret en tierras americanas, se presenta a los compradores dos estampas de tema americano: el gíbaro y la esclava de Puerto Rico. Posteriormente, mientras el tema histórico quedó marginado en los grabados impresos, no ocurrió así -ya lo sabemos-con la temática americana que apareció en dos grupos de grabados más: un par de láminas sobre Perú y las seis láminas -anunciadas como las primeras de una serie de dieciséis que no se publicaron- de las castas americanas.

No parece descabellado considerar la publicación de la portada de la obra como una advertencia y guía de un cambio de orientación de la misma, probablemente -aunque no tengamos datos para asegurarlo- en un coyuntura crítica en donde se abrían los caminos para futuras entregas (temas de los "dominios", perspectiva histórica, división estamental y ayuda en los dibujos por parte de los compradores). Evidentemente esta ampliación de los objetivos tendría como último y principal fin mejorar la rentabilidad económica de la obra, pero no deja de ser significativo que el propio autor considerase necesario llamar la atención al comprador de que de los territorios peninsulares, desde el punto de vista espacial, se iba a pasar a la representación de los territorios de la Monarquía. Si la confusión podía existir, y Juan de la Cruz se cuidaba muy mucho en aclararla, la diferencia entre los términos "España" y Monarquía existía y quedaba patente incluso con la propia utilización de los términos, hablándose de dos realidades distintas: la española y la de sus dominios. Pero 
la constatación de un hecho no implica una justificación del mismo y es aquí donde, creo, se encuentra el quid de la cuestión. Que se constaten dos realidades no implica ni que se tome partido por una de ellas ni que se intenten integrar ${ }^{95}$.

Las siguientes preguntas que habría que hacerse son ¿cuáles son las pretensiones de Juan de la Cruz con respecto a esta realidad autorepresentada?, ¿qué pretende el autor visibilizando esta diferencia? Para su contestación conviene tener en cuenta la reacción que causó la Colección de trajes en el máximo responsable de la política española del momento, el conde de Floridablanca.

Glendinning, Harris y Russel nos informan ${ }^{96}$ que Floridablanca tenía en su despacho, entre otras obras de arte, algunos grabados de esta Colección. Este dato será posteriormente interpretado por Molina y Vega como una prueba de que la Colección, de manera más o menos subrepticia tenía un fin propagandístico. Aunque tal posibilidad es probable, si bien dichos autores no tienen en cuenta las posibles consecuencias de la censura del Mapa de América del Sur, para lo que ahora nos ocupa resulta más interesante constatar de manera indudable que el Primer Secretario de Estado estaba de acuerdo con lo representado. Evidentemente, no podemos asegurar, y ni siquiera insinuar, que Floridablanca fuera el inspirador de la Colección pero de lo que no cabe ninguna duda era de que compartía los presupuestos, fueran éstos los que fueran, del autor de la obra. Si comparamos el discurso desplegado por Juan de la Cruz a lo largo de su obra (que se ha analizado más arriba) con los planteamientos ideológicos que pudiera respaldar Floridablanca desde el poder, se observará que no existen contradicciones entre ambos y que ninguna de las ideas expuestas por Cruz podría ser censurada por el conde desde su alto cargo político-administrativo. Es más, alguna de estas ideas sería francamente apoyada por el Primer Secretario de Estado. El planteamiento de un conjunto de grabados en donde se diese a conocer, imitando a Francia y a otros países europeos, los trajes típicos de los españoles sin caer en la descripción miserabilista que la simple visión comercial impedía y en donde se destacasen los aspectos modernizadores con una clase media ciudadana ociosa, a imitación de la parisina, y una galería de oficios urbanos que podemos denominar casi costumbrista eran del agrado de Floridablanca. Por otra parte, los tipismos taurinos y las «rarezas» de los trajes locales, además de poder leerse como particularidades regionales interesantes y dignas de ser conocidas, podía también interpretarse como una diversidad dentro de la unidad en una perfecta armonía de las relaciones entre campo y ciudad representados en el conjunto de la Colección de manera equitativa. Por otra parte, la ausencia del estamento eclesiástico y noble no tendría por qué disgustar al conde en

95 Esta consciencia entre las diferentes realidades espaciales se constatará también en el resto de los anuncios localizados insertados en la Gaceta de Madrid. Si bien es cierto que en las representaciones de la española y la india de Perú (Gaceta de Madrid, 31.3.1780) se habla de "coleccion de trages de España", en los tres anuncios de las representaciones de castas la denominación de la Colección cambia por la de "coleccion de trages de España y sus dominios" (Gaceta de Madrid, 22.6.1784, 19.11.1784 y 17.6.1785). Para, posteriormente y hasta el final de los anuncios localizados, volver a la antigua denominación de "coleccion de trages de España", salvo en la denominación de las dos estampas inmediatamente posteriores a las de las castas, denominada con un discreto "colección de trages grabada por D. Juan de la Cruz" (Gaceta de Madrid, 15.11.1785).

96 Glendinning, Nigel, Harris, Enriqueta y Russel, Francis: «Lord Grantham and the Taste for Velázquez: the Electrical Eel of the day», Burlington Magazine, 1.159 (1999), p. 601. Tomado de Molina y VeGA, op. cit. (nota 11), p. 193. 
una visión modernizadora de la sociedad española en donde los elementos que podían interpretarse como más retrógrados dejaban paso a la parte más dinámica de la sociedad formada por vendedores, comerciantes y miembros de la mesocracia urbana. Si a esto le unimos las posibilidades de exportación que la traducción al francés de los títulos de los grabados habilitaba y, por otra parte, un cierto carácter de representación de todos los grabados que obviaba los elementos más negativos (fealdad, miseria o, en general, suciedad) en pos de unos grabados que, como también apuntan Molina y Vega, casi podían interpretarse como actores que se caracterizaban como los personajes representados -no hay que olvidar en este punto que nos encontramos con varias estampas en las que, literalmente, se representaban a los grandes actores de la escena hispana caracterizados en diversos personajes-, el resultado final de la Colección se nos presenta como una gran representación idealizada de los componentes de una sociedad. ¿Pero esta sociedad idealizada era la española?

En la difícil contestación de esta pregunta, desde nuestro punto de vista, también existe una perfecta armonía entre Cruz y Floridablanca. La sociedad idealizada en la Colección no pretendía ser la española, sino la de la Monarquía Hispánica. Con tal idealización políticamente significativa las láminas que salieron a la luz representaban tipos de toda la Monarquía no exclusivamente de la sociedad española, circunscrita a los territorios peninsulares y de los dos archipiélagos. La propia descripción de la Colección en la Gaceta de Madrid, como se ha visto, era clara al respecto. Por un lado estaba España y por otro sus dominios pero ambas realidades se inscribían en una realidad superior, la Monarquía. Además, la utilización por parte de Juan de la Cruz del término "dominio" resultaba también altamente significativa por el giro, no sólo pero también terminológico, que se había producido de la visión que desde la Península se tenía de los territorios americanos. Durante el siglo XVIII el calificativo de Indias tuvo que compartir espacio con el de "dominios" reflejando este término el cambio de visión que se había realizado desde Madrid respecto a los territorios americanos de la Monarquía vistos, a causa de la influencia francesa e inglesa, más como espacios subordinados al servicio de la Península que como miembros de un todo común. A pesar de los intentos pretendidamente integradores que se observan en las Cortes de Cádiz, durante la época ilustrada las relaciones con la América hispana se establecen sobre parámetros más explotadores, aunque consideramos aventurado denominarlos como "colonialistas". La pretendida ingenuidad del calificativo "dominio" en la Colección de trajes denota una realidad de explotación acorde con la política ilustrada sobre América.

Aun así, como no podía ser de otra manera, los caracteres explotadores de la relación con las Indias no aparecen visualizados en la obra de Juan de la Cruz. En otro proceso de idealización, las estampas americanas (las seis de castas, las dos de Puerto Rico y las dos de Perú) no ofrecen elementos críticos ni negativos, haciéndose hincapié en la riqueza de la oligarquía limeña y tratando con dignidad a los elementos indígenas y esclavos. En el fondo todos, los peninsulares, los insulares y los americanos, era dignos súbditos de Carlos III. Así, por encima de la posible identificación nacional, se ubicaba una identificación dinástica típica del Antiguo Régimen a pesar de que, en un rasgo marcadamente ilustrado, sí se producían cambios de representa- 
ción ideal de la sociedad ya apuntados, como el desarrollo de las clases medias y el mundo urbano y la marginación icónica de los estamentos privilegiados.

El espacio se acaba y no hemos tratado sobre la recepción de la Colección ni la evolución de la misma. Pero más allá de las estrecheces del espacio, nuestro conocimiento está limitado por la escasez de las fuentes. Sabemos que no fue bien recibida entre algunos de los cenáculos artísticos del momento, pero estas críticas no parece que resulten muy significativas a nivel general. A este nivel el éxito de la Colección parece indudable. La nota que el propio Juan de la Cruz inserta en uno de sus cuadernos llamando la atención sobre la presencia de ediciones piratas desde el extranjero corroboraría el éxito de las estampas y otro tanto indicará la aparición de la Colección de trajes de Antonio Rodríguez a principios del siglo XIX. Ahora bien, en el ámbito de la recepción de los discursos, el componente coyuntural e histórico es incluso más importante que la ideología subyacente en los mismos, por lo que las posibles interpretaciones de la colección a la altura del final de reinado de Carlos III no tendrían por qué ser idénticas a las explicaciones dadas en la coyuntura gaditana, en los momentos de reacción absolutista fernandina, durante la consolidación de liberalismo en España o, si me apuran, a inicios del siglo XXI... 